\title{
On the robustness of aerosol effects on an idealized supercell storm simulated with a cloud system-resolving model
}

\author{
H. Morrison \\ National Center for Atmospheric Research, 3090 Center Green Dr., Boulder, CO 80301, USA \\ Correspondence to: H. Morrison (morrison@ucar.edu)
}

Received: 29 February 2012 - Published in Atmos. Chem. Phys. Discuss.: 24 April 2012

Revised: 21 July 2012 - Accepted: 10 August 2012 - Published: 23 August 2012

\begin{abstract}
A cloud system-resolving model (the Weather Research and Forecasting model) with $1 \mathrm{~km}$ horizontal grid spacing is used to investigate the response of an idealized supercell storm to increased cloud droplet concentrations associated with polluted conditions. The primary focus is on exploring robustness of simulated aerosol effects in the face of complex process interactions and feedbacks between the cloud microphysics and dynamics. Simulations are run using sixteen different model configurations with various microphysical or thermodynamic processes modified or turned off. Robustness of the storm response to polluted conditions is also explored for each configuration by performing additional simulations with small perturbations to the initial conditions. Differences in the domain-mean accumulated surface precipitation and convective mass flux between polluted and pristine conditions are small for almost all model configurations, with relative differences in each quantity generally less than $15 \%$. Configurations that produce a decrease (increase) in cold pool strength in polluted conditions also tend to simulate a decrease (increase) in surface precipitation and convective mass flux. Combined with an analysis of the dynamical and thermodynamic fields, these results indicate the importance of interactions between microphysics, cold pool evolution, and dynamics along outflow boundaries in explaining the system response. Several model configurations, including the baseline, produce an overall similar storm response (weakening) in polluted conditions despite having different microphysical or thermodynamic processes turned off. With hail initiation turned off or the hail fallspeed-size relation set to that of snow, the model produces an invigoration instead of weakening of the storm in polluted conditions. These results highlight the difficulty of foreseeing impacts of changes to model parameterizations and isolating process interactions
\end{abstract}

that drive the system response to aerosols. Overall, these findings are robust, in a qualitative sense, to small perturbations in the initial conditions. However, there is sensitivity in the magnitude, and in some cases sign, of the storm response to polluted conditions with small perturbations in the temperature of the thermal used to initiate convection (less than $\pm 0.5 \mathrm{~K}$ ) or the vertical shear of the environmental wind $( \pm 5 \%)$. It is concluded that reducing uncertainty in simulations of aerosol effects on individual deep convective storms will likely require ensemble methods in addition to continued improvement of model parameterizations.

\section{Introduction}

Numerous studies using cloud system-resolving (or cloudresolving) models have indicated that aerosols can affect the characteristics of moist deep convection through their impact on cloud microphysics (e.g., Wang, 2005; Khain et al., 2005; Lynn et al., 2005; Seifert and Beheng, 2006; van den Heever et al., 2006; Teller and Levin, 2006; Phillips et al., 2007; Tao et al., 2007; Fan et al., 2007; Lee et al., 2008; Khain 2009; Khain and Lynn, 2009; Fan et al., 2009; Noppel et al., 2010; Storer et al., 2010; Ekman et al., 2011; Lee 2011; Lebo and Seinfeld, 2011; hereafter LS11; see Levin and Cotton, 2009 and Tao et al., 2012 for reviews). Understanding and quantifying the response to aerosols is challenging because of the complexity of process interactions involving aerosols, liquid and ice-phase cloud and precipitation microphysics, surface-atmosphere exchange, radiation, and dynamics over a wide range of spatiotemporal scales (e.g., Noppel et al., 2010; Seifert et al., 2012; Tao et al., 2012). 
Given this complexity, it seems likely that multiple interaction pathways act synergistically to drive the response of deep convection to aerosols, with specific process pathways that may differ from case to case. Therefore, it is not surprising that various modeling studies have shown a wide range of aerosol impacts on surface precipitation and convective intensity, not only in magnitude but also sign (see Table 5 in Tao et al., 2007 and Table 4 in Tao et al., 2012). System complexity also leads to rapid, nonlinear growth of small perturbations and solution drift among different realizations of deep convective storms (Hack and Pedretti, 2000; Tan et al., 2004; Zhang et al., 2007; Wang et al., 2012). This can make it difficult to ascertain robustness of aerosol impacts based on single realizations (c.f., Morrison and Grabowski, 2011), which is the approach utilized by most studies.

Despite this uncertainty, there is agreement among several studies that invigoration of deep convection occurs in polluted conditions (e.g., Koren et al., 2005; Khain et al., 2005; van den Heever et al., 2006; Seifert and Beheng, 2006; Tao et al., 2007; Rosenfeld et al., 2008; Lee et al., 2008; Khain and Lynn, 2009; LS11; Ekman et al., 2011; Fan et al., 2012; Lee, 2011), depending in part upon environmental vertical wind shear, relative humidity, and/or convective available potential energy (CAPE) (Seifert and Beheng 2006; Fan et al., 2009; Khain, 2009; Lee, 2011; Storer et al., 2010). These studies have often attributed invigoration to increased latent heating and buoyancy associated with delayed warm rain formation (droplet collision-coalescence) in polluted conditions and hence greater lofting of cloud water and its subsequent freezing and intensification of ice processes above the $0{ }^{\circ} \mathrm{C}$ level (Khain et al., 2005; Seifert and Beheng, 2006; Rosenfeld et al., 2008; Fan et al., 2012; LS11; Ekman et al., 2011). As pointed out by Rosenfeld et al. (2008) and LS11, delayed warm rain formation also results in increased condensate loading which has opposing effects on buoyancy; whether or not there is invigoration or weakening depends upon the relative balance of these effects, all else being equal.

Other process interactions have also been identified that can drive convective invigoration or weakening in polluted conditions. For example, Tao et al. (2007) and Lee et al. (2008) found an increase in convective mass flux and surface precipitation in polluted conditions using both liquidonly and mixed-phase microphysics schemes. These results suggest a more complicated picture of invigoration than the simple mechanism of increased latent heating associated with freezing and more vigorous ice processes described by Rosenfeld et al. (2008). Tao et al. (2007) and Lee et al. (2008) found that convective invigoration occurred because of stronger cold pools and increased low-level convergence in polluted conditions caused by enhanced evaporation of cloud water and rain. Similar invigoration associated with secondary convection was noted by Khain et al. (2005) and Lynn et al. (2005). However, van den Heever et al. (2007) simulated a weakening of convection generated along cold pool boundaries with increased aerosol loading. The criti- cal role of feedback between microphysics and dynamics in driving the system response to aerosols, rather than microphysical process interactions alone, was demonstrated by Slawinska et al. (2009). They showed almost no impact on surface precipitation distribution and amount with increased aerosols when the dynamical flow field was fixed (representing a squall line), with much larger effects when the flow field was modified. Overall, the complicated role of interactions between microphysics, cold pools, and storm dynamics again highlights complexity of deep convective storms, leading to difficulty in understanding and generalizing aerosol effects on such systems.

Comparison of the response of deep convection to increased aerosols using models with microphysics schemes of varying sophistication has been the subject of several recent studies (Khain and Lynn, 2009; Khain et al., 2009; Li et al., 2009a, b; Fan et al., 2012; LS11; Lebo et al., 2012). In these studies, detailed bin microphysics schemes often simulated a much different response than simpler bulk schemes. For example, LS11 found that a bin scheme produced invigoration of convection in polluted conditions, while a bulk scheme produced weakening (e.g., Fig. 7 in LS11). Specific reasons for the different responses using bin and bulk schemes were unclear in these studies. Nevertheless, identifying specific process interactions that drive the convective response to aerosols in these models is critical for determining why they produce such dramatically different results. It is also helpful as a way to address uncertainty; if the parameterization of some process is poorly constrained yet found to be critical in explaining the system response, this process represents a key uncertainty in quantifying aerosol effects. However, determining cause and effect is challenging because of the system complexity and myriad feedbacks. For example, increased latent heating in updrafts with a change in aerosols can affect buoyancy and hence updraft velocity (Rosenfeld et al., 2008), but conversely, an increase in updraft velocity can increase condensation and latent heating rates. In addition to making it difficult to separate cause and effect, this complexity may often preclude a priori prediction of the magnitude or even sign of the convective response to model parameter changes (Noppel et al., 2010), or changes in other aspects such as environmental conditions. Thus, it is challenging to tune parameters in bulk microphysics schemes so that they produce results consistent with bin schemes.

The purpose of this study is to investigate the robustness of aerosol effects on deep convection simulated using a cloud system-resolving model in the context of these issues. Results are analyzed in terms of changes in meteorological fields and process rates between pristine and polluted conditions. In contrast to previous studies, simulations with pristine and polluted conditions are performed using a large number of different model configurations with various microphysical and thermodynamic processes systematically modified or turned off. Implications for understanding the role of these processes in the overall system response to 
Table 1. List of all model configurations tested.

\begin{tabular}{|c|c|}
\hline Configuration & Description \\
\hline BASE & Baseline model configuration \\
\hline BASE-MOD & $\begin{array}{l}\text { Baseline model configuration, but the difference between moderately polluted } \\
\text { and pristine conditions }\end{array}$ \\
\hline NOFRZ_LH & $\begin{array}{l}\text { Latent heating due to freezing of cloud liquid water and rain turned off (this } \\
\text { includes homogeneous and heterogeneous freezing as well as riming) }\end{array}$ \\
\hline NODEP_LH & Latent heating due to vapor deposition onto cloud ice, snow, and hail turned off \\
\hline NOSUB LCC & Latent cooling due to sublimation of cloud ice, snow, and hail turned off \\
\hline NOMLT_LC & Latent cooling due to melting of cloud ice, snow, and hail turned off \\
\hline NOEVAPR & Latent cooling due to rain evaporation turned off \\
\hline NOEVAP & Latent cooling due to evaporation of cloud water and rain turned off \\
\hline NOLOAD & $\begin{array}{l}\text { Condensate loading due to cloud liquid water and rain neglected in the buoyancy } \\
\text { term of the vertical momentum equation }\end{array}$ \\
\hline NOHAIL & Hail initiation turned off \\
\hline LIQAUTO & Autoconversion of cloud water to rain turned off \\
\hline HAILF & Fallspeed-size relation for hail set to that of snow \\
\hline LIQ & Liquid-only, all ice microphysics turned off \\
\hline NOHET & Heterogeneous freezing of cloud water turned off \\
\hline NOACC & Accretion of cloud water by rain turned off \\
\hline NORIME & Riming of cloud water and rain by snow and hail turned off \\
\hline NOCPOOL & Latent cooling due to evaporation, sublimation, and melting turned off \\
\hline
\end{tabular}

aerosols are discussed. Finally, robustness of these results is explored in the context of small perturbations to initial conditions. As will be shown, the rapid growth of small perturbations in model fields can obscure the effects of aerosols and make generalization of these effects difficult.

This paper describes simulations of the response of an idealized supercell storm to polluted versus pristine conditions using a bulk microphysics scheme (Morrison et al., 2009) implemented in the Weather Research and Forecasting model (WRF; Skamarock et al., 2008). One might anticipate aerosol effects to be relatively small for supercell storms compared to other convective systems, since the mesoscale convective updrafts in these storms are strongly driven by stretching and tilting of horizontal vorticity associated with environmental shear in addition to buoyancy effects (e.g., Klemp, 1987). Nonetheless, this setup was chosen following recent studies comparing simulations of aerosol impacts on supercell storms using bulk and bin microphysics schemes (Khain and Lynn 2009; LS11; Lebo et al., 2012). The goal of this study is not to provide quantitative estimates of aerosol impacts on supercell storms per se, but rather to explore uncertainty in the storm response in the face of system complexity. There has been little study of aerosol effects on deep convection in this context, despite the implications for robustness and understanding of model simulations of these effects.

The paper is organized as follows. Section 2 describes the experimental design. Results are presented in Sect. 3. Discussion and conclusions are provided in Sect. 4.

\section{Experimental design}

In this study, the Advanced Research WRF version 3.1 (Skamarock et al., 2008) is utilized. The model setup is similar to the idealized supercell case available as part of the WRF modeling package and used previously by Khain and Lynn (2009) and LS11. The model is three-dimensional, nonhydrostatic, and compressible. The governing equations are solved using a time-split third-order Runge-Kutta integration scheme and sub-steps for the acoustic modes. Horizontal grid spacing is $1 \mathrm{~km}$ and vertical grid spacing is approximately $500 \mathrm{~m}$. While previous studies have documented sensitivity of deep convection to horizontal grid spacings less than $1 \mathrm{~km}$ (e.g., Bryan et al., 2003), analysis of the sensitivity of aerosol effects to model resolution is beyond the scope of this paper. The model top is a rigid lid at $20 \mathrm{~km}$. A Rayleigh gravity wave absorber with damping coefficient of $0.003 \mathrm{~s}^{-1}$ is applied between $15-20 \mathrm{~km}$ to prevent spurious wave reflection. The model horizontal domain is $200 \times 200 \mathrm{~km}^{2}$, with open boundary conditions along all lateral boundaries. Note that open lateral boundary conditions allow nonzero horizontally-averaged vertical velocity and horizontal convergence/divergence, potentially leading to differences in domain-mean thermodynamic and dynamic forcings among simulations. This contrasts with periodic lateral boundaries, in which horizontally-averaged vertical velocity must be close to zero if the upper and lower boundaries 
Table 2. Summary of results for the various model configurations. Presented results include the change in domain-mean accumulated surface precipitation $(\triangle \mathrm{PRE})$, convective mass flux at a height of $8.25 \mathrm{~km}\left(\Delta \mathrm{MF}_{\mathrm{c}}\right)$, and lowest-level potential temperature averaged within the cold pool $(\Delta \theta)$ between polluted and pristine conditions (POLL minus PRIS). For $\Delta \mathrm{MF}_{\mathrm{c}}$ and $\Delta \theta$, results are averaged between $t=90$ and $120 \mathrm{~min}$, while $\Delta \mathrm{PRE}$ is the difference in accumulated precipitation at $t=120 \mathrm{~min}$. The top, middle, and lower values in each box are results from simulations with maximum $\theta^{\prime}$ of the thermal to initiate convection of $3,3.5$, and $2.5 \mathrm{~K}$, respectively. The $\%$ change in each quantity relative to PRIS is given in parentheses.

\begin{tabular}{|c|c|c|c|}
\hline Configuration & $\begin{array}{l}\Delta \mathrm{PRE} \\
0.01 \times \mathrm{mm}\end{array}$ & $\begin{array}{l}\Delta \mathrm{MF}_{\mathrm{c}} \\
0.01 \times \mathrm{kg} \mathrm{m}^{-2} \\
\mathrm{~s}^{-1}\end{array}$ & $\begin{array}{l}\Delta \theta \\
\mathrm{K}\end{array}$ \\
\hline BASE & $\begin{array}{l}-7.42(-5.9) \\
-5.33(-4.0) \\
-10.26(-8.6)\end{array}$ & $\begin{array}{l}-0.95(-8.7) \\
-0.52(-4.8) \\
-1.09(-10.5)\end{array}$ & $\begin{array}{l}0.44(9.8) \\
0.44(9.9) \\
0.52(11.5)\end{array}$ \\
\hline BASE-MOD & $\begin{array}{l}-2.90(-2.2) \\
0.00(0.0) \\
-2.00(-1.7)\end{array}$ & $\begin{array}{l}-0.88(-8.1) \\
-0.19(-1.8) \\
-0.31(-3.0)\end{array}$ & $\begin{array}{l}0.26(6.0) \\
0.26(5.8) \\
0.20(4.5)\end{array}$ \\
\hline NOFRZ_LH & $\begin{array}{l}-3.02(-2.4) \\
-2.55(-2.0) \\
-5.56(-4.8)\end{array}$ & $\begin{array}{l}-0.69(-7.5) \\
-0.44(-4.7) \\
-1.05(-11.5)\end{array}$ & $\begin{array}{l}0.32(6.9) \\
0.32(7.0) \\
0.39(8.6)\end{array}$ \\
\hline NODEP_LH & $\begin{array}{l}-10.02(-8.4) \\
-7.55(-6.1) \\
-9.52(-8.7)\end{array}$ & $\begin{array}{l}-0.27(-2.5) \\
0.29(2.7) \\
-0.30(-2.8)\end{array}$ & $\begin{array}{l}0.41(9.6) \\
0.39(9.2) \\
0.44(10.2)\end{array}$ \\
\hline NOSUB_LC & $\begin{array}{l}-10.87(-7.9) \\
-10.08(-7.1) \\
-11.66(-9.1)\end{array}$ & $\begin{array}{l}-0.66(-6.4) \\
-0.65(-6.2) \\
-0.73(-7.2)\end{array}$ & $\begin{array}{l}0.54(12.3) \\
0.50(11.5) \\
0.55(12.6)\end{array}$ \\
\hline NOMLT_LC & $\begin{array}{l}-3.81(-3.1) \\
-3.25(-2.6) \\
-4.99(-4.4)\end{array}$ & $\begin{array}{l}-0.88(-8.3) \\
-0.83(-7.7) \\
-0.80(-7.9)\end{array}$ & $\begin{array}{l}0.43(10.9) \\
0.38(9.7) \\
0.45(11.3)\end{array}$ \\
\hline NOEVAPR & $\begin{array}{l}-3.05(-2.7) \\
-3.19(-2.7) \\
-2.85(-2.7)\end{array}$ & $\begin{array}{l}-0.91(-7.8) \\
-0.76(-6.4) \\
-1.24(-10.8)\end{array}$ & $\begin{array}{l}0.01(0.5) \\
0.08(3.3) \\
0.08(3.7)\end{array}$ \\
\hline NOEVAP & $\begin{array}{l}3.98(3.0) \\
5.46(3.9) \\
5.23(4.2)\end{array}$ & $\begin{array}{l}0.86(6.5) \\
0.99(7.3) \\
1.22(9.6)\end{array}$ & $\begin{array}{l}0.04(1.9) \\
0.06(2.5) \\
0.02(0.9)\end{array}$ \\
\hline NOLOAD & $\begin{array}{l}-3.22(-1.4) \\
-0.91(-0.4) \\
-3.09(-1.4)\end{array}$ & $\begin{array}{l}-0.93(-7.8) \\
-0.44(-3.7) \\
-0.36(-3.2)\end{array}$ & $\begin{array}{l}0.01(0.4) \\
0.00(0.0) \\
0.03(0.9)\end{array}$ \\
\hline NOHAIL & $\begin{array}{l}5.44(19.2) \\
3.41(11.0) \\
3.67(13.7)\end{array}$ & $\begin{array}{l}0.80(8.2) \\
0.00(0.0) \\
0.53(5.6)\end{array}$ & $\begin{array}{l}-0.19(-7.8) \\
-0.11(-4.5) \\
-0.10(-4.0)\end{array}$ \\
\hline LIQAUTO & $\begin{array}{l}2.55(2.5) \\
1.86(1.7) \\
2.99(3.2)\end{array}$ & $\begin{array}{l}-0.14(-1.5) \\
-0.21(-2.2) \\
-0.20(-2.2)\end{array}$ & $\begin{array}{l}-0.08(-2.0) \\
-0.09(-2.3) \\
-0.06(-1.6)\end{array}$ \\
\hline HAIL_F & $\begin{array}{l}8.08(46.6) \\
8.54(47.1) \\
7.26(45.7)\end{array}$ & $\begin{array}{l}0.16(1.6) \\
0.24(2.4) \\
0.01(0.1)\end{array}$ & $\begin{array}{l}-0.01(-0.4) \\
-0.01(-0.5) \\
-0.03(-1.1)\end{array}$ \\
\hline LIQ & $\begin{array}{l}-1.17(-1.1) \\
0.08(0.1) \\
-4.48(-3.1)\end{array}$ & $\begin{array}{l}-0.15(-1.6) \\
-0.48(-4.9) \\
-1.94(-11.3)\end{array}$ & $\begin{array}{l}0.34(7.3) \\
0.28(6.1) \\
0.39(8.3)\end{array}$ \\
\hline NOHET & $\begin{array}{l}2.98(2.3) \\
4.54(3.3) \\
5.40(5.9)\end{array}$ & $\begin{array}{l}-1.03(-10.2) \\
-0.77(-7.6) \\
-1.31(-13.2)\end{array}$ & $\begin{array}{l}0.15(3.2) \\
0.26(5.6) \\
0.28(5.9)\end{array}$ \\
\hline NOACC & $\begin{array}{l}-0.07(-0.1) \\
3.08(5.0) \\
-3.72(-7.1)\end{array}$ & $\begin{array}{l}0.15(1.6) \\
0.56(5.8) \\
0.09(1.1)\end{array}$ & $\begin{array}{l}0.10(2.4) \\
0.13(3.1) \\
0.05(1.1)\end{array}$ \\
\hline NORIME & $\begin{array}{l}-8.84(-10.7) \\
-9.82(-11.9) \\
-8.47(-11.7)\end{array}$ & $\begin{array}{l}-1.19(-11.6) \\
-1.14(-10.8) \\
-1.49(-14.7)\end{array}$ & $\begin{array}{l}0.33(9.6) \\
0.34(9.8) \\
0.43(12.1)\end{array}$ \\
\hline NOCPOOL & $\begin{array}{l}-2.03(-1.6) \\
-0.76(-0.6) \\
-3.34(-2.9)\end{array}$ & $\begin{array}{l}-0.14(-1.1) \\
0.02(0.1) \\
-0.71(-5.6)\end{array}$ & $\begin{array}{l}0.00(0.00) \\
0.00(0.00) \\
-0.06(-2.7)\end{array}$ \\
\hline
\end{tabular}

are rigid ${ }^{1}$. However, differences in horizontally-averaged vertical velocity between the simulations here are very small at all vertical levels (generally much less than a few $\mathrm{mm} \mathrm{s}^{-1}$ ), and hence this issue will not be discussed further. As is common in idealized supercell simulations, radiation, Coriolis acceleration, and surface heat fluxes are neglected for simplicity, and the lower boundary is free slip. It is noted that surface heat fluxes and surface friction may impact the response of cold pool properties to aerosols, but are not expected to affect overall conclusions of this study. Horizontal and vertical turbulent diffusion are calculated using a 1.5 order TKE scheme (Skamarock et al., 2008).

The thermodynamic sounding of the environment (Fig. 1) is from Weisman and Klemp (1982, 1984), with a CAPE of approximately $2200 \mathrm{~J} \mathrm{~kg}^{-1}$. These simulations use the quarter-circle supercell hodograph of Weisman and Rotunno (2000; see their Fig. 3b), except that the shear is extended to a height of $7 \mathrm{~km}$ instead of $6 \mathrm{~km}$ following the standard WRF idealized supercell case setup. This hodograph features a quarter-circle shear from the surface to $2 \mathrm{~km}$ and unidirectional shear above $2 \mathrm{~km}$, with a length of $40 \mathrm{~m} \mathrm{~s}^{-1}$ (Fig. 2).

Convection is triggered using an initial thermal perturbation with maximum perturbation potential temperature $\left(\theta^{\prime}\right)$ of $3 \mathrm{~K}$ centered at a height of $1.5 \mathrm{~km}$ and varying as the cosine squared to the edge, with a horizontal radius of $10 \mathrm{~km}$ and a vertical radius of $1.5 \mathrm{~km}$. Similar thermal characteristics were used to initiate convection in Fan et al. (2009), Lynn and Khain (2009), and LS11, among others. Sensitivity to the $\theta^{\prime}$ of the initial thermal is described in Sect. 3.3 as a way to investigate robustness of aerosol effects to small perturbations in the initial conditions. All simulations are integrated for $2 \mathrm{~h}$.

While it is recognized that idealized and "real case" model setups can give different sensitivities, the idealized framework is used here for consistency with previous studies (Seifert and Beheng 2006; Khain and Lynn 2009, LS11) and to allow a large number of model runs to be performed. It is also important to distinguish between aerosol impacts on isolated deep convective storms, as simulated here and in many previous studies, and impacts over larger spatiotemporal scales which include feedbacks between individual storms and the larger-scale thermodynamic and dynamic environment (c.f., Grabowski 2006; Morrison and Grabowski 2011; van den Heever et al., 2011; Seifert et al., 2012). This point is discussed further in Sect. 3.3.

The microphysics scheme used for these simulations is the two-moment bulk scheme described by Morrison et al. (2009) and Morrison and Milbrandt (2011). For

\footnotetext{
1 Insignificant but nonzero horizontally-averaged vertical velocities using WRF with periodic lateral boundaries are possible because its dynamical governing equations are compressible. For the anelastic approximation with periodic lateral boundaries, the horizontally-averaged vertical velocity must be exactly zero (to within numerical limits of the anelastic pressure solver).
} 


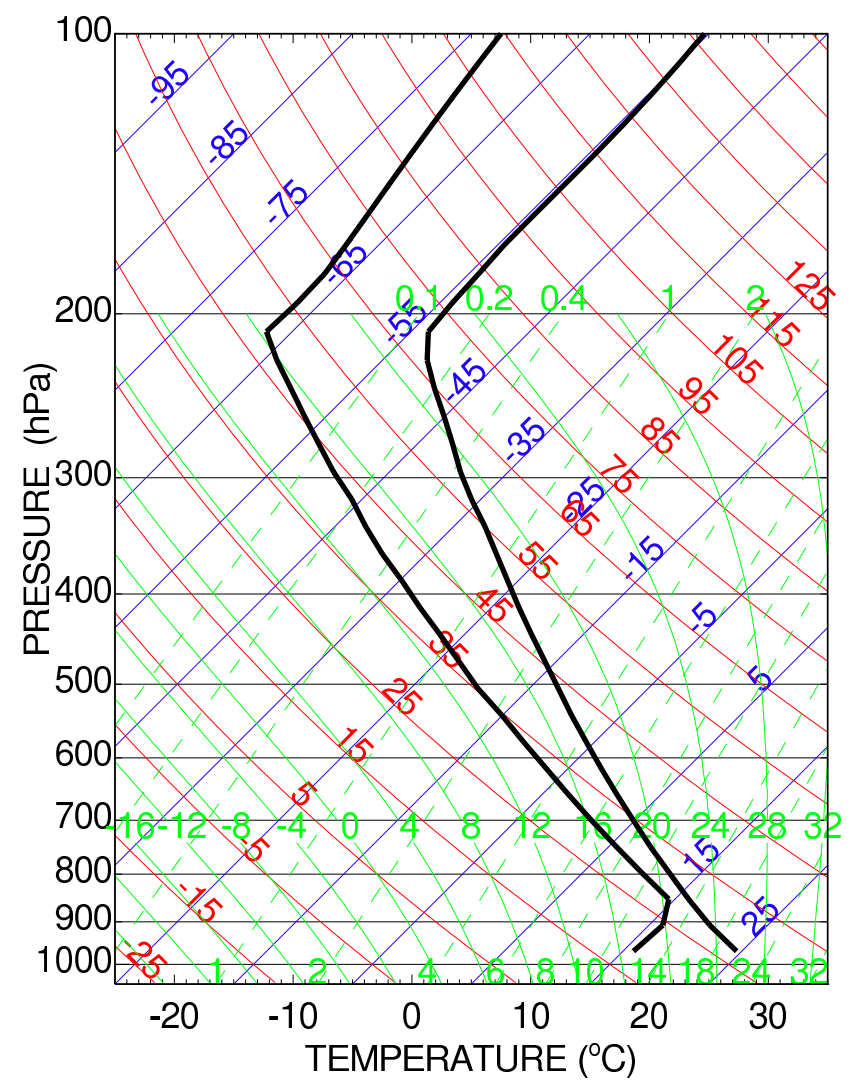

Fig. 1. Skew-T diagram of the initial environmental sounding.

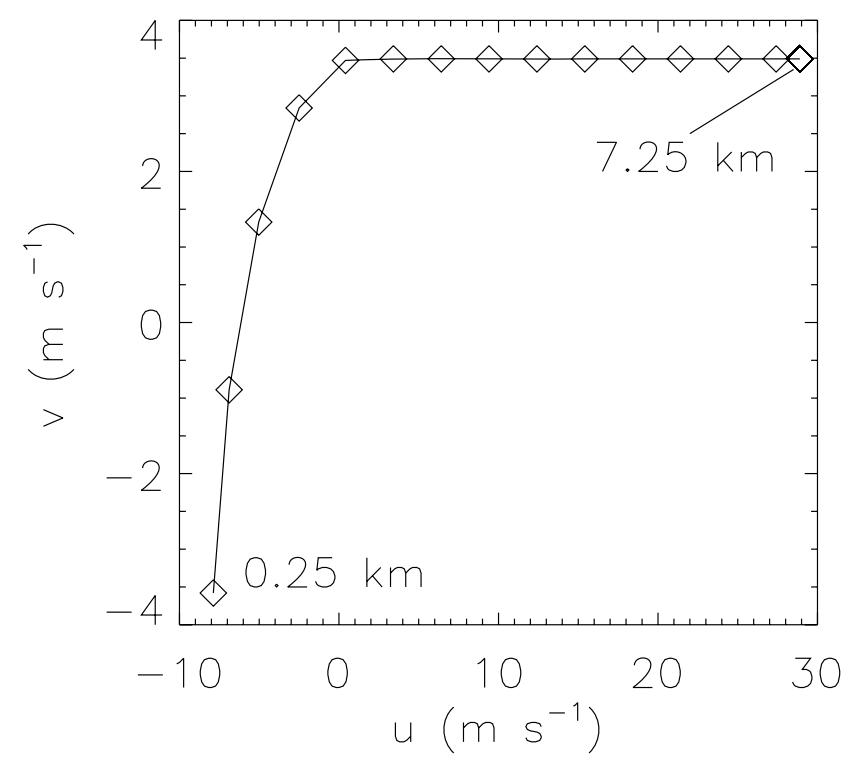

Fig. 2. Hodograph indicating $u$ and $v$ winds of the initial environment. Diamonds represent winds at $0.5 \mathrm{~km}$ intervals between heights of 0.25 and $7.25 \mathrm{~km}$. simplicity, cloud-aerosol interactions are not explicitly included; instead, different cloud droplet concentrations are prescribed to mimic the effects of different $\mathrm{CCN}$ concentrations in pristine and polluted conditions following Khain and Lynn (2009). Note that this scheme, like most bulk microphysics schemes, applies saturation adjustment to calculate cloud water condensation and evaporation (i.e., any excess vapor above water saturation is condensed within one time step, or cloud water is evaporated so that conditions are water saturated within a time step). Thus, the effects of changes in droplet concentration on droplet condensation/evaporation are neglected; the implications of this assumption are detailed in Lebo et al. (2012). Explicit inclusion of cloud-aerosol interactions would add more complexity and uncertainty to a problem that is already highly challenging, and therefore would be unlikely to alter the main findings herein pertaining to difficulties in understanding aerosol effects on deep convection. Here, droplet concentration is set to 50,250 , and $750 \mathrm{~cm}^{-3}$ for pristine, moderately polluted, and highly polluted conditions. Although $50 \mathrm{~cm}^{-3}$ is somewhat less than in-situ observations showing average droplet concentrations generally larger than $100 \mathrm{~cm}^{-3}$ in non-precipitating shallow cumuli in remote continental locations (e.g., see Tables 1 and 2 in Blyth and Latham, 1991), a goal of this study is to understand model behavior over a wide range of conditions. Moreover, droplet concentrations in supercells are uncertain given the lack of measurements in these storms.

In addition to the baseline model configuration, pairs of sensitivity tests are performed assuming either pristine or highly polluted conditions but with various microphysical and thermodynamic processes turned off or modified. These configurations are summarized in Table 1. It is emphasized that the goal of these sensitivity configurations is not to quantify uncertainty associated with specific process parameterizations per se, but rather to investigate process interactions that drive the system response to polluted conditions in the face of system complexity. Thus, several configurations do not have a realistic representation of physical processes (e.g., liquid-only simulations), and the ensemble spread of results should not be taken as an estimate of the uncertainty associated with physical parameterizations.

\section{Results}

\subsection{Baseline model configuration}

The baseline model configuration (BASE) produces a small but general weakening of the storm in highly polluted (POLL) relative to moderately polluted (MOD) and pristine (PRIS) conditions, similar to LS11 who also simulated aerosol effects on a supercell storm using WRF with the same microphysics scheme. Weakening in polluted conditions was also shown by Fan et al., 2012 using this scheme to simulate 

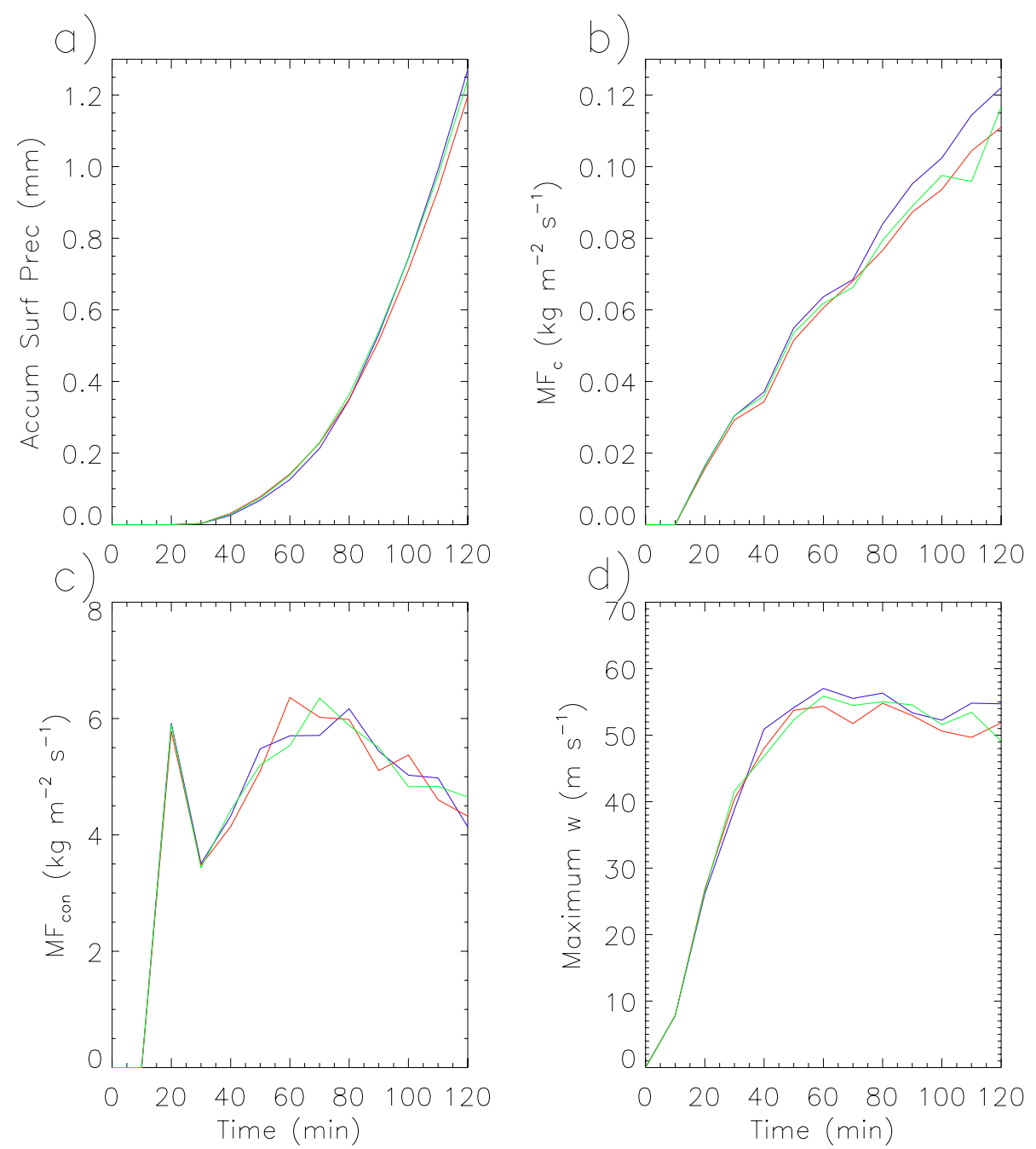

Fig. 3. Timeseries of (a) domain-mean accumulated surface precipitation, (b) domain-mean convective mass flux, $\mathrm{MF}_{\mathrm{c}}$, (c) convective mass flux averaged only within convective cores, $\mathrm{MF}_{\mathrm{con}}$, and (d) domain-maximum vertical velocity, $\mathrm{w}$, for the baseline model configuration (BASE). Results for pristine, moderately polluted, and highly polluted conditions are shown by blue, green, and red lines, respectively. Results for $\mathrm{MF}_{\mathrm{c}}$ and $\mathrm{MF}_{\mathrm{con}}$ at a height of $8.25 \mathrm{~km}$ are presented.

a large mesoscale convective system. Overall, differences between POLL and MOD are similar to differences between POLL and PRIS, but with a somewhat reduced magnitude of effects.

Storm weakening is illustrated by timeseries of domainaveraged accumulated surface precipitation and convective mass flux, $\mathrm{MF}_{\mathrm{c}}$, at a height of $8.25 \mathrm{~km}$ for PRIS, MOD, and POLL (Fig. 3). Here $\mathrm{MF}_{\mathrm{c}}$ is defined as the sum of the mass flux for grid points with vertical velocity, w, greater than $2 \mathrm{~m} \mathrm{~s}^{-1}$, divided by the total horizontal area of the domain. $\mathrm{MF}_{\mathrm{c}}$ at a height of $8.25 \mathrm{~km}$ is representative of overall changes in convective mass flux between PRIS, MOD, and POLL; $\mathrm{MF}_{\mathrm{c}}$ is reduced by a similar magnitude in POLL across most of the mid- and upper-troposphere between about 4 and $11 \mathrm{~km}$ compared to MOD or PRIS (Fig. 4). However, overall differences in the domain-averaged $\mathrm{MF}_{\mathrm{c}}$ and surface precipitation between POLL, MOD, and PRIS are small. Interestingly, domain-mean accumulated surface precipitation is slightly larger in POLL than MOD or PRIS before $t=80 \mathrm{~min}$, but smaller after this time, while $\mathrm{MF}_{\mathrm{c}}$ is greater over the duration of the simulations. For example, after about $t=90 \mathrm{~min}$, relative differences in $\mathrm{MF}_{\mathrm{c}}$ (at a height of $8.25 \mathrm{~km}$ ) and accumulated precipitation are about 6-10\% between PRIS and POLL. Note that local differences in precipitation and $\mathrm{MF}_{\mathrm{c}}$ between PRIS, MOD, and POLL are much larger, which is primarily attributed to shifts in the location of the left-moving storm as detailed below. A reduction of convective intensity and precipitation in polluted conditions for this case, which is strongly sheared, is qualitatively consistent with results of Fan et al. (2009, see Figs. 2 and 5 therein). Similarly, Seifert and Beheng (2006) simulated a decrease of surface precipitation with aerosol 


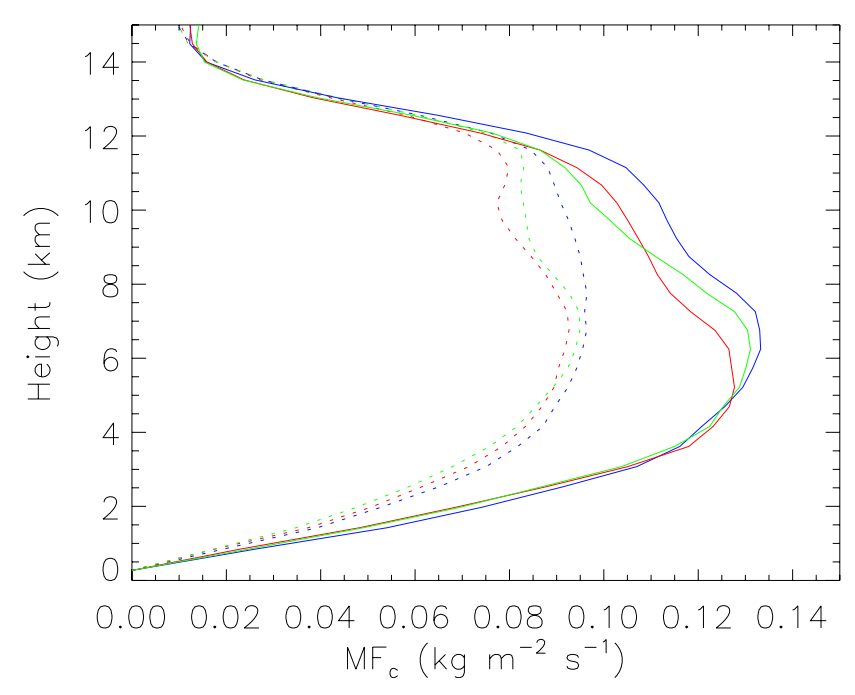

Fig. 4. Vertical profiles of the horizontally-averaged convective mass flux, $\mathrm{MF}_{\mathrm{c}}$, for the baseline model configuration (BASE) at $t=90$ (dotted) and $120 \mathrm{~min}$ (solid). Results for pristine, moderately polluted, and highly polluted conditions are shown by blue, green, and red lines, respectively.

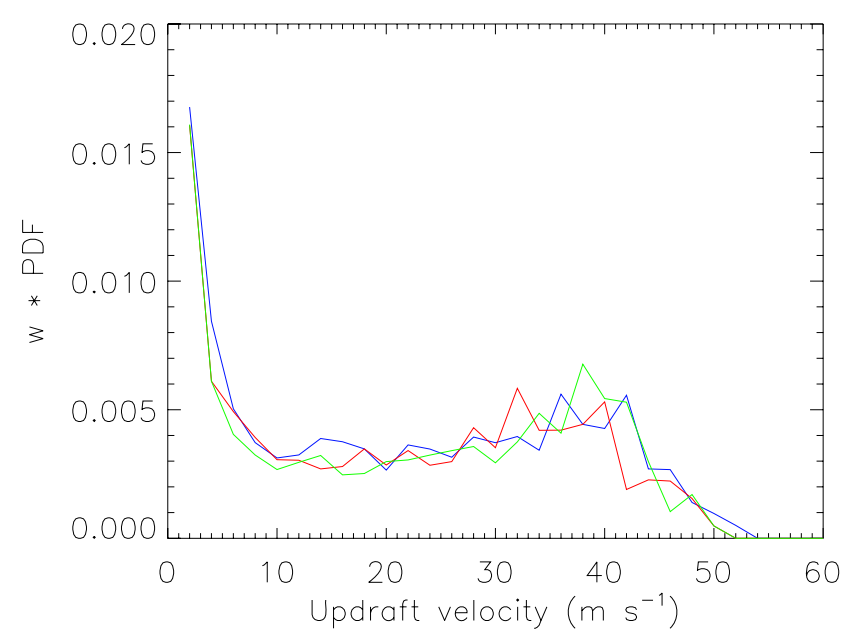

Fig. 5. Probability density functions (PDFs) of updraft velocity (multiplied by the value of vertical velocity) for the baseline model configuration (BASE) at a height of $8.25 \mathrm{~km}$ and between $t=90$ and $120 \mathrm{~min}$. Results for pristine, moderately polluted, and highly polluted conditions are shown by blue, green, and red lines, respectively.

loading under strongly sheared conditions, but either a small decrease or increase in maximum updraft speed at low and high CAPE, respectively (see Fig. 12 therein). Other simulations of supercell storms showed an increase of convective intensity in polluted compared to pristine conditions and either an increase or decrease of precipitation depending upon the environmental relative humidity (Khain and Lynn, 2009; LS11).

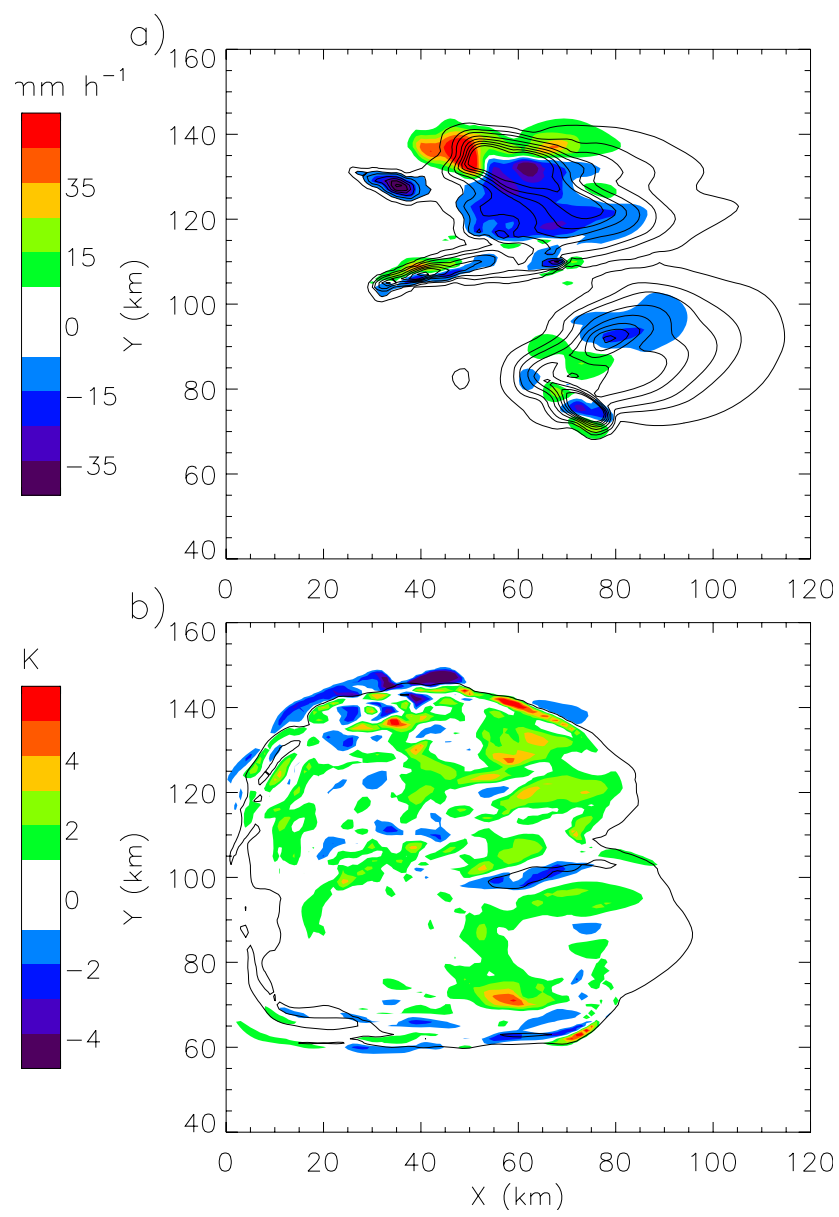

Fig. 6. (a) Surface precipitation rate and (b) lowest-level $\theta^{\prime}$ for the BASE configuration at $t=120 \mathrm{~min}$. Colored contours indicate differences between polluted and pristine simulations (POLL minus PRIS). Black contour lines indicate (a) surface precipitation rate (contour interval of $5 \mathrm{~mm} \mathrm{~h}^{-1}$, from $1 \mathrm{~mm} \mathrm{~h}^{-1}$ up to $36 \mathrm{~mm} \mathrm{~h}^{-1}$ ), and (b) cold pool boundary (defined by the $-2 \mathrm{~K} \theta^{\prime}$ isotherm) in PRIS at $t=120 \mathrm{~min}$.

Differences in $\mathrm{MF}_{\mathrm{c}}$ between PRIS, MOD, and POLL are relatively insensitive to the choice of threshold $w$ for defining convective updrafts (from 1-5 $\mathrm{m} \mathrm{s}^{-1}$ ), and fairly smooth over time (Fig. 3b). Differences in domain-maximum vertical velocity also appear to be fairly robust, but with more temporal variability than the differences in $\mathrm{MF}_{\mathrm{c}}$ (Fig. 3d). In contrast, differences between POLL, MOD, and PRIS in the mass flux averaged within convective cores $^{2}$ (Fig. 3c), as well as fraction of the domain or total number of grid points with convective updrafts (not shown), exhibit considerable temporal variability and large sensitivity to perturbed initial conditions. Thus, $\mathrm{MF}_{\mathrm{c}}$ appears to be a more robust measure of

\footnotetext{
${ }^{2}$ Convective cores are defined using a threshold $w>2 \mathrm{~ms}^{-1}$. Similar results are obtained if convective cores are defined as columns in which average vertical velocity between 3.3 and $11 \mathrm{~km}$ exceeds $1 \mathrm{~m} \mathrm{~s}^{-1}$ following van den Heever et al. (2006) and LS11.
} 

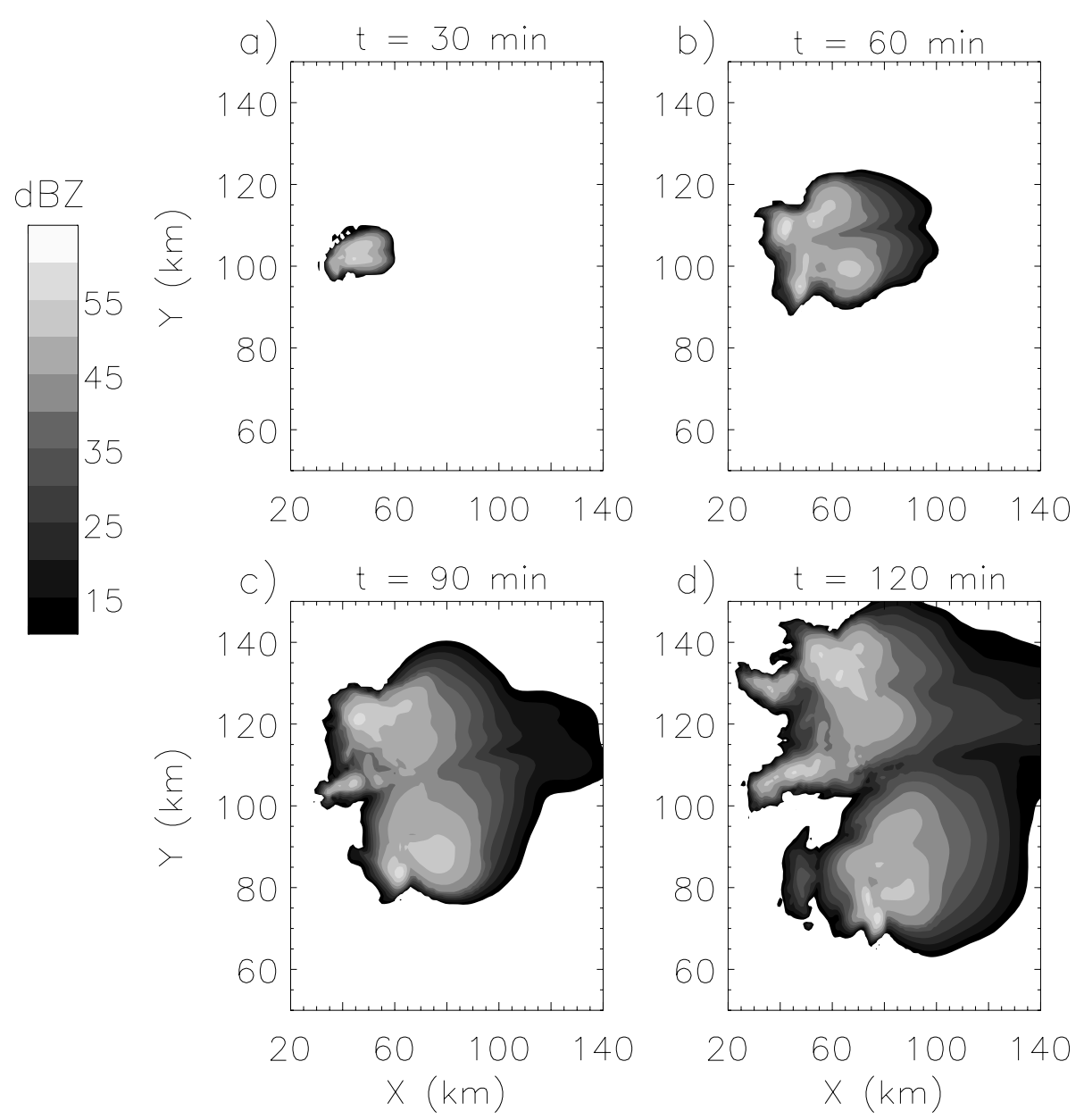

Fig. 7. Horizontal plots of lowest model level $(\sim 250 \mathrm{~m})$ radar reflectivity at $t=$ (a) 30 , (b) 60 , (c), 90 , and (d) $120 \mathrm{~min}$ for the BASE configuration and pristine (PRIS) conditions.

differences in overall convective intensity compared to these other quantities (this is apparent across the depth of the troposphere).

Probability density functions (PDFs) of updraft velocity at a height of $8.25 \mathrm{~km}$ and between $t=90$ and $120 \mathrm{~min}$, normalized by the total number of grid points and multiplied by vertical velocity, indicate the contribution of updrafts with a particular velocity to $\mathrm{MF}_{\mathrm{c}}$. There is considerable variability across the spectrum of updraft velocities in terms of differences between POLL, MOD, and PRIS (Fig. 5). The decrease of $\mathrm{MF}_{\mathrm{c}}$ in POLL occurs at various updraft velocities, with no preferential reduction apparent for a particular range of velocities.

Given that differences between MOD and POLL are similar to differences between PRIS and POLL (but with a somewhat reduced magnitude), the remainder of the paper focuses on PRIS and POLL. Differences in storm structure and evolution between PRIS and POLL are further illustrated by horizontal contour plots of surface precipitation rate and $\theta^{\text {c }}$ at the lowest model level (Fig. 6). Overall storm features (e.g., splitting supercell) are strongly driven by the thermodynamic and shear profiles of the environment and are therefore similar among the simulations. However, notable differences between PRIS and POLL become apparent after about $30 \mathrm{~min}$, coinciding with the development of precipitation. Splitting of the mesoscale updraft into right-and leftmoving storms, which is expected given the shear profile of the environment (e.g., Klemp and Wilhelmson 1978), begins around $t=30 \mathrm{~min}$ (Fig. 7). Most differences between PRIS and POLL in terms of storm structure are associated with the left-moving storm (Fig. 6a). In particular, the axis of heavy precipitation is shifted to the right (i.e., greater $\mathrm{X}$ ) by approximately $10-20 \mathrm{~km}$ in PRIS, with an overall increase of about $15 \%$ associated with this storm (explaining most of the $6 \%$ increase in domain-mean surface precipitation between PRIS and POLL). PRIS also has a substantially stronger cold pool than POLL over most of the cold pool region, especially after $t=60 \mathrm{~min}$ (Fig. 6b). In a modeling study of aerosol effects on a splitting storm, Storer et al. (2010) also found greater sensitivity of the left-moving than the right-moving 

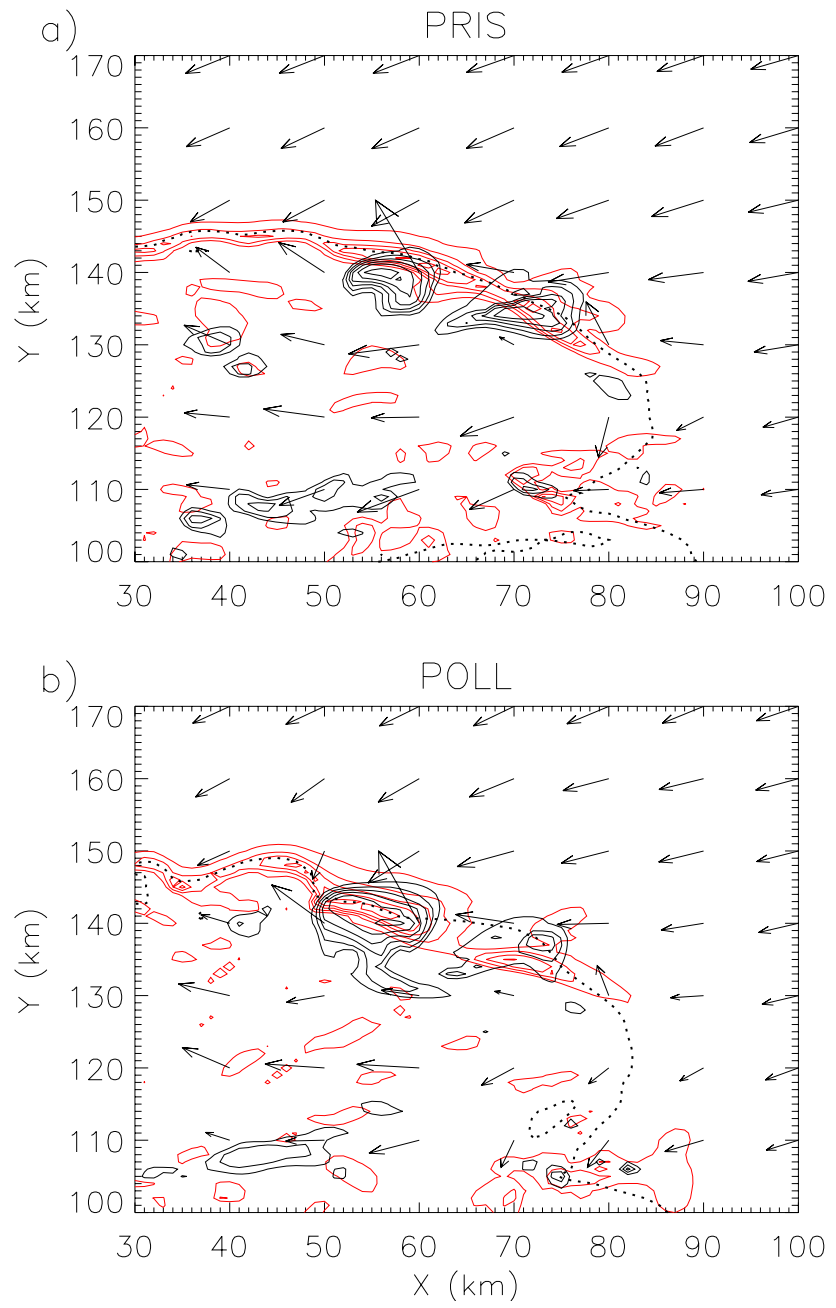

Fig. 8. Upward vertical velocity at altitudes of $1.5 \mathrm{~km}$ (red contours) and $5 \mathrm{~km}$ (black contours), storm-relative low-level horizontal wind (vectors), and cold pool boundary denoted by the $-2 \mathrm{~K} \theta^{\prime}$ isotherm (black dotted contour) for the BASE configuration at $t=120 \mathrm{~min}$ and (a) pristine (PRIS) and (b) highly polluted (POLL) conditions. Contour intervals are $5 \mathrm{~m} \mathrm{~s}^{-1}$ for the $5 \mathrm{~km}$ vertical velocity (contours starting at $5 \mathrm{~m} \mathrm{~s}^{-1}$ ) and $2 \mathrm{~m} \mathrm{~s}^{-1}$ for the $1.5 \mathrm{~km}$ vertical velocity (contours starting at $1 \mathrm{~m} \mathrm{~s}^{-1}$ ).

storm, and weaker cold pools in polluted compared to pristine conditions. While they also found a decrease in precipitation with increased aerosol loading consistent with the present study, there was no clear relationship of convective updraft strength with aerosol concentration.

The importance of interactions between cold pool strength, outflow boundaries, and storm dynamics is suggested by plots of the low-level $(1.5 \mathrm{~km})$ and mid-level $(5 \mathrm{~km})$ vertical velocity, low-level horizontal wind, and cold

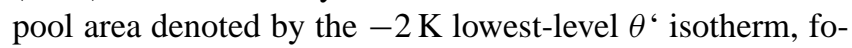
cusing on the left-moving storm (Fig. 8). Stronger cold air outflow in PRIS leads to a more vigorous region of lowlevel convergence and upward vertical velocity along the cold pool edge compared to POLL, especially toward the forward flank. Stronger low-level convergence in this region in turn feeds moist, high $\theta_{e}$ air into the storm, given the (stormrelative) low-level horizontal flow from the upper right-tolower left. Correspondingly, the left-moving mesoscale updraft, which becomes elongated at the cold pool edge after $t=60 \mathrm{~min}$ and separates into two distinct updraft cells by $t=120 \mathrm{~min}$ in both POLL and PRIS, is stronger at mid- and upper-levels in PRIS than POLL. This difference is most apparent toward the forward flank, and is consistent with the rightward shift of heavy precipitation.

Overall, these results suggest the importance of interactions between microphysics, cold pool evolution, and flow in and around outflow boundaries in explaining differences between PRIS and POLL. The importance of these interactions in driving sensitivity of supercell storms to microphysics parameter changes has also been noted by several previous studies (e.g., Gilmore and Wicker 1998; Gilmore et al., 2004; van den Heever et al., 2004; Milbrandt and Yau 2006; Dawson et al., 2010; James and Markowski 2010; Storer et al., 2010; Morrison and Milbrandt 2011). Qualitatively, an increase in surface precipitation associated with stronger cold pools and increased low-level convergence is consistent with Tao et al. (2007), Lee et al. (2008), and Lee (2011), who studied the response of (non-supercellular) mesoscale convective systems to increased aerosol loading. However, these studies found that polluted conditions led to stronger cold pools, which is opposite of the results here and those described by Storer et al. (2010). It is unclear if these contrasting results are due to different cases (e.g., supercellular versus linear mesoscale convection), or use of different models.

\subsection{Sensitivity to model configuration}

Sensitivity tests described next investigate the importance of specific microphysical and thermodynamic processes in driving the system response to polluted versus pristine conditions. A list of the sixteen model configurations is provided in Table 1; a summary of differences in domain-averaged $\mathrm{MF}_{\mathrm{c}}$, accumulated surface precipitation, and lowest-level $\theta$ within the cold pool between POLL and PRIS for all simulations is shown in Table 2. Hereafter, $\mathrm{MF}_{\mathrm{c}}$ at a height of $8.25 \mathrm{~km}$ is used as a representative measure of general convective intensity. Changes in $\mathrm{MF}_{\mathrm{c}}$ at this height are consistent with overall convective mass flux changes between PRIS and POLL across the mid- and upper-troposphere in these simulations (e.g., see Fig. 4a for BASE). $\mathrm{MF}_{\mathrm{c}}$ also provides a more robust measure of changes in convective intensity compared to the other dynamical quantities described previously.

The various model configurations produce a wide range of aerosol impacts on accumulated surface precipitation, $\mathrm{MF}_{\mathrm{c}}$, and cold pool strength, although the effects are small $(<15 \%)$ in most configurations. Here, cold pool strength

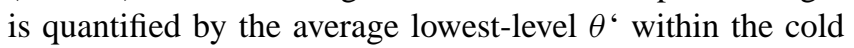
pool (defined as the region with $\theta^{\prime}-2 \mathrm{~K}$ ). Most, but not all, 

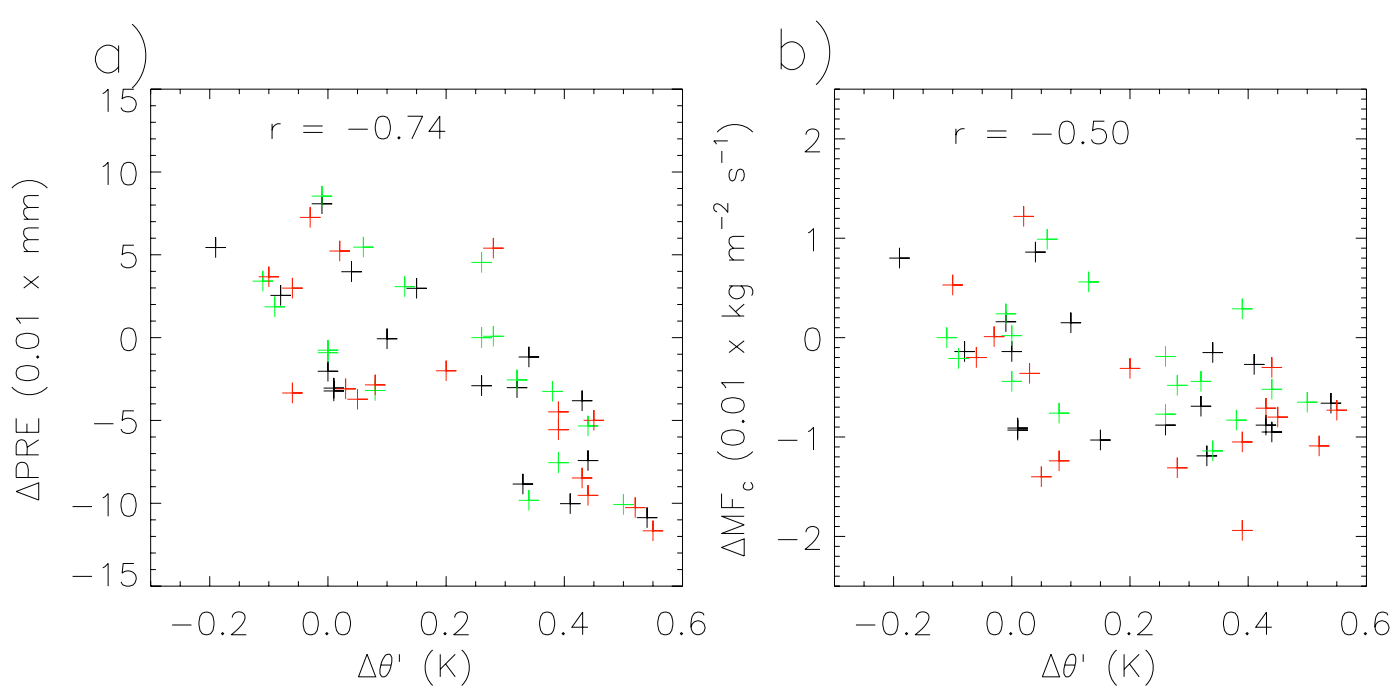

Fig. 9. Scatterplots of the changes between polluted and pristine conditions (POLL minus PRIS) in (a) domain-mean accumulated surface precipitation $(\triangle \mathrm{PRE})$ versus low-level potential temperature averaged within the cold pool $\left(\Delta \theta^{\prime}\right)$ and (b) domain-mean convective mass flux at a height of $8.25 \mathrm{~km}\left(\Delta \mathrm{MF}_{\mathrm{c}}\right)$ versus $\Delta \theta^{\prime}$, for all configurations shown in Table $2 . \Delta \mathrm{MF}_{\mathrm{c}}$ and $\Delta \theta^{\prime}$ are averaged from $t=90$ to 120 min; $\triangle \mathrm{PRE}$ is the difference at $t=120 \mathrm{~min}$. Results with maximum $\theta^{\prime}$ of $2.5,3$, and $3.5 \mathrm{~K}$ for the thermal used to initiate convection are shown in red, black, and green, respectively.

model configurations that produce a substantial decrease in cold pool strength between PRIS and POLL (i.e., a difference in average cold pool $\theta$ of at least $\sim 0.2 \mathrm{~K}$ ) also produce a decrease in $\mathrm{MF}_{\mathrm{c}}$ and surface precipitation (Fig. 9). Similar differences between PRIS and POLL are apparent for other measures of cold pool strength. For example, cold pool area is generally larger in simulations with lower average cold pool $\theta^{\prime}$, although relative differences between PRIS and POLL are small (generally less than $15 \%$ ). Considering all simulations, there is fairly strong anti-correlation $(r=-0.70)$ between the change (POLL minus PRIS) in accumulated surface precipitation and the change in cold pool $\theta^{\prime}$, and somewhat weaker anti-correlation $(r=-0.50)$ between the change in $\mathrm{MF}_{\mathrm{c}}$ and the change in cold pool $\theta$, (Fig. 9). Structural differences between PRIS and POLL in simulations with large differences in cold pool $\theta^{\prime}$ are also similar, namely, a rightward shift in heavy precipitation, enhanced low-level convergence along the cold pool edge, and elongation and strengthening of the left-moving mesoscale updaft toward the forward flank in PRIS compared to POLL as seen in Fig. 8 for BASE. These simulations therefore provide additional evidence for the importance of interactions between microphysics, cold pools, and dynamics in driving the system response. However, it is important to point out that correlation does not necessarily imply causation; while greater precipitation and convective intensity can be driven by enhanced low-level convergence associated with stronger cold pools, differences in cold pool strength can in turn be driven by differences in precipitation.

For model configurations that produce a weaker cold pool response between PRIS and POLL, there is either an in- crease or decrease of $\mathrm{MF}_{\mathrm{c}}$ and surface precipitation (Table 2; Fig. 9). Many of these changes are not robust, with large differences in the magnitude and in some cases the sign of changes in $\mathrm{MF}_{\mathrm{c}}$ and/or surface precipitation between PRIS and POLL with small perturbations to initial conditions (Sect. 3.3). The configuration with cooling due to rain evaporation turned off (NOEVAPR) produces weak cold pools and little difference in cold pool characteristics between PRIS and POLL, indicating that enhanced evaporation of rain in PRIS drives stronger cold pools. This result is consistent with increased warm rain production through autoconversion in PRIS, leading to reduced mean raindrop size and enhanced evaporation. However, it is interesting that NOEVAPR, as well as the configuration with cloud water and rain neglected in the buoyancy term of the vertical momentum equation (NOLOAD), still produce a robust decrease of $\mathrm{MF}_{\mathrm{c}}$ and accumulated precipitation in polluted conditions despite the lack of obvious differences in cold pool characteristics and lowlevel convergence. Furthermore, the pattern of precipitation and dynamical changes between POLL and PRIS (Fig. 10) is much different for NOEVAPR (and NOLOAD), with its weak cold pools, than in BASE (compare Figs. 10 and 8). The implication is that different interaction pathways are able to act in different model configurations to drive a similar overall system response (i.e., a small weakening in polluted conditions), illustrating network-like behavior. The ability of the model to produce a similar response with key processes turned off, due to compensation by other processes, is similar to the concept of "buffering", in which the system-wide response to a perturbation is damped due to compensation by 

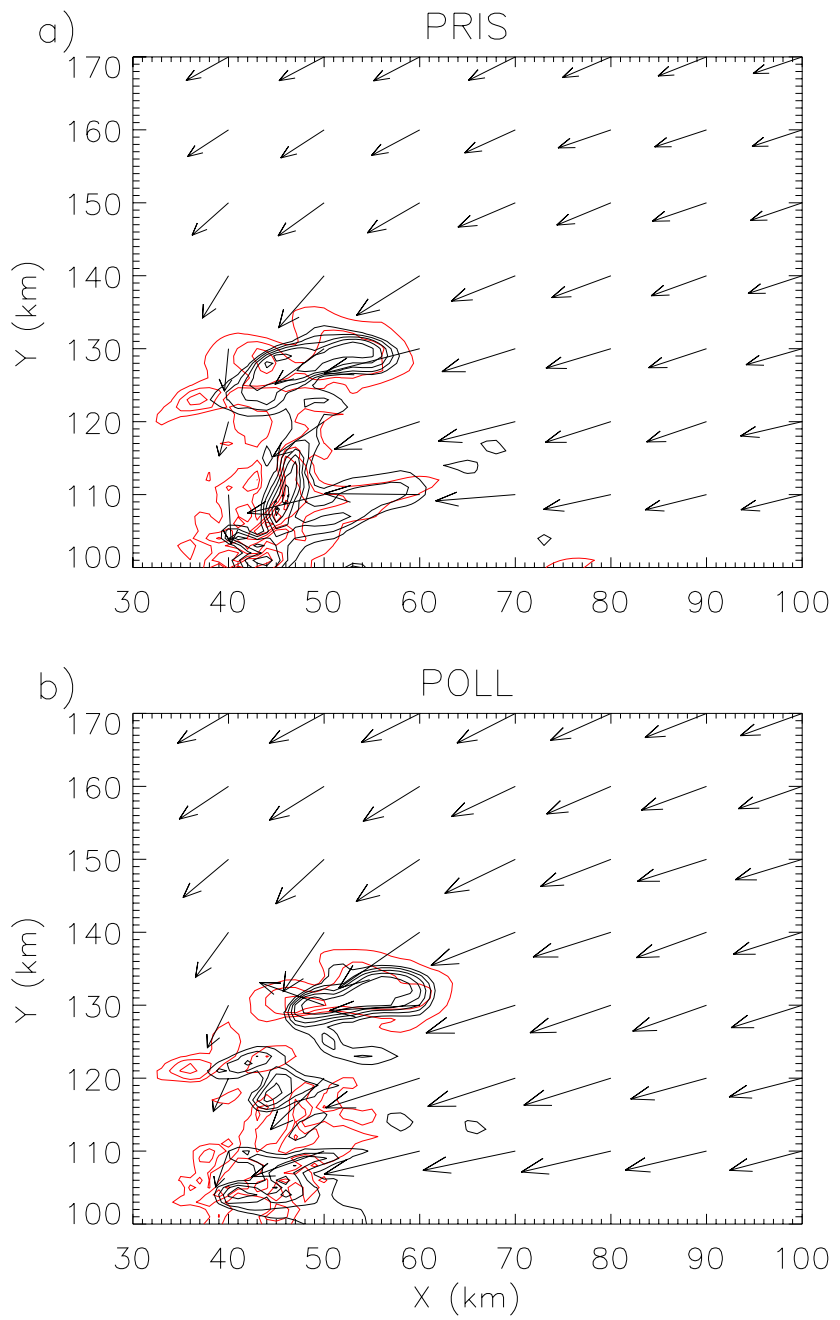

Fig. 10. As in Fig. 8, except for the model configuration with cooling by rain evaporation turned off (NOEVAPR).

myriad process interactions within the system (Stevens and Feingold, 2009).

Note that the interaction pathways driving the system response in some configurations may not necessarily occur in reality, given unrealistic physical representations in these configurations (e.g., neglect of rain evaporation in NOEVAPR). Nevertheless, the key point is that even with large changes to the process parameterizations across different configurations (i.e., turning the process off), in many instances the model produces a similar response due to compensating process interactions. The implication is that different parameter settings (or formulations) for a process may have limited impact on the overall system response, even when the differences are large.

Overall invigoration instead of weakening when hail initiation is turned off (NOHAIL), the hail fallspeed-size relation is set to that of snow (HAILF), or cloud water and rain evaporation is turned off (NOEVAP) suggest the impor- tance of these processes. These results plausibly suggest that differences in precipitation fallspeed are an important factor in determining the sign of the response of $\mathrm{MF}_{\mathrm{c}}$ and surface precipitation. Both LIQ (liquid-only) and BASE, as well as other configurations with hail, produce relatively fast-falling precipitation and weakening of convection in POLL, while the configurations with slow-falling precipitation above the melting layer (NOHAIL, HAILF) produce invigoration. The configurations with slow-falling precipitation also produce much less surface precipitation (explaining the larger relative changes in surface precipitation between POLL and PRIS; see Table 2) compared to simulations with faster-falling precipitation. Subsequently, altered interactions between cold pools, outflow boundaries, and storm dynamics may help to explain the different responses of $\mathrm{MF}_{\mathrm{c}}$ and surface precipitation to polluted and pristine conditions in these configurations.

As described in the Introduction, latent heating and condensate loading drive buoyancy perturbations and hence can influence convective vertical velocity (e.g., Rosenfeld et al., 2008; LS11). Diagnostic analysis of latent heating and condensate loading has been used as a way to identify processes that drive the deep convective response to aerosols in previous studies (Khain et al., 2005; LS11, Fan et al., 2012). Horizontally-averaged latent heating rates and hydrometeor mixing ratios are analyzed herein for consistency with these studies, although it is noted that including only grid points with convective updrafts $\left(w>2 \mathrm{~m} \mathrm{~s}^{-1}\right)$ in the averaging gives similar differences between PRIS and POLL.

Figure 11 includes latent heating contributions from individual processes (freezing of cloud water and rain, vapor deposition onto ice, and cloud liquid water condensation) for BASE at $t=120 \mathrm{~min}$, as well as the total latent heating (i.e., the sum of these contributions). Total latent heating is greater in PRIS than POLL (by $\sim 5-10 \%$ ) below about $8.5 \mathrm{~km}$, consistent with the differences in $\mathrm{MF}_{\mathrm{c}}$ (Fig. 3b, Fig. 4). Freezing, liquid condensation (vapor conversion to liquid), and ice deposition (vapor conversion to ice) all have important contributions to differences in total latent heating between PRIS and POLL for BASE. Differences in liquid condensation drive differences in latent heating below the melting layer $(\sim 4 \mathrm{~km})$, while differences in freezing, and, to a lesser extent, ice deposition, are more important above $4 \mathrm{~km}$.

Based on these heating profiles, one might anticipate that differences in heating due to ice deposition and especially freezing are important in explaining the increased $\mathrm{MF}_{\mathrm{c}}$ above $4 \mathrm{~km}$ in PRIS relative to POLL. However, the test with no latent heat release due to freezing (NOFRZLH) produces remarkably similar differences in total latent heating between PRIS and POLL compared to BASE (compare Figs. 12 and 11), and a similar convective response in terms of $\mathrm{MF}_{\mathrm{c}}$ (see Table 2). This occurs because other processes compensate when latent heating associated with freezing is turned off. In particular, differences in heating from liquid condensation and ice deposition between PRIS and POLL in NOFRZ_LH 
are much larger compared to BASE, resulting in similar differences in total latent heating. A similar situation occurs in the configuration with latent heating from deposition turned off (NODEP_LH); other processes (especially latent heating due to condensation) compensate for the lack of heating from ice deposition to give similar differences in profiles of total latent heating (compare Figs. 13 and 11). This compensation of process interactions again highlights system complexity and the difficulty of isolating specific processes driving the system response. These results suggest that it is generally not possible to estimate the impact of a change in some process without rigorous sensitivity testing of that process in the context of the system as a whole. This is broadly consistent with Noppel et al. (2010), who argued that system complexity made it difficult to foresee the impact of changes in model parameters on simulations of aerosol effects in a hailstorm.

An analysis of hydrometeor mixing ratio profiles, following the approach of LS11, reveals more condensate in PRIS than POLL below 6-8 km for BASE, with greater amounts in POLL at upper levels (Fig. 14). Similar differences occur when only grid points with convective updrafts are included in the averaging. However, there is considerable temporal variability in differences of condensate between PRIS and POLL; for example, there is a change in the sign of these differences between $t=90$ and $120 \mathrm{~min}$ for NOHAIL (not shown). In general, there does not appear to be much correspondence between greater condensate loading and reduced convective intensity. This finding contrasts with LS11, who found that condensate loading was greater in polluted compared to pristine conditions and concluded that this difference was the primary driver of the weaker convection in polluted conditions using the Morrison et al. (2009) bulk microphysics scheme.

\subsection{Sensitivity to perturbed initial conditions}

Small perturbations in model fields grow rapidly at convective scales, resulting in solution drift over time and limiting predictability of the flow (Lorenz 1969; Zhang et al., 2003, 2007; Wang et al., 2012). Thus, it can be difficult to robustly quantify aerosol effects in the face of this solution drift (Morrison and Grabowski, 2011). This may be especially problematic for quantifying and generalizing aerosol effects on deep convection because the magnitude of these effects is generally small, relative to other factors such as environmental shear or relative humidity (e.g., Khain and Lynn, 2009; Khain et al., 2009). To further investigate this issue, the model configurations described previously were rerun with small changes to initial conditions. This was done by performing two additional sets of simulations (both PRIS and POLL) for each configuration, with the maximum $\theta^{\prime}$ of the thermal used to initiate convection changed from $3 \mathrm{~K}$ to either 2.5 or $3.5 \mathrm{~K}$.

Overall, the findings reported in Sects. 3.1 and 3.2 are robust, in a qualitative sense, to small perturbations of the ini- tial thermal. However, there are changes in the magnitude of differences in domain-mean surface precipitation and $\mathrm{MF}_{\mathrm{c}}$ for most configurations, and in some cases changes in sign of these differences (see Table 2). For example, relative changes between PRIS and POLL in BASE vary from -4.0 to $-8.6 \%$ for accumulated surface precipitation and -4.8 to $-10.5 \%$ for $\mathrm{MF}_{\mathrm{c}}$ (at a height of $8.25 \mathrm{~km}$ ) with perturbations to the initial $\theta^{\prime}$. Differences in other measures of convective intensity, such as the updraft mass flux averaged only within convective cores, exhibit even greater variability (not shown). Given that the impacts of changes in initial $\theta^{\prime}$ are more or less random (see Fig. 9), it appears that sensitivity to initial $\theta^{\prime}$ occurs mostly as a result of limited predictability associated with rapid perturbation growth, rather than sensitivity to initial $\theta^{\prime}$ in a predictable sense. The implication is that the growth of small perturbations resulting from any model changes (e.g., parameter settings, resolution, time step, initial or boundary conditions, etc.) could potentially produce substantial changes in the system response to aerosols.

To test this idea, two additional pairs of simulations were performed using BASE and pristine or polluted conditions with an initial maximum $\theta^{\prime}$ of $3 \mathrm{~K}$, but with the vertical shear in the environmental $u$-component wind either decreased or increased by $5 \%$. Consistent with rapid perturbation growth in model fields regardless of the initial perturbation source, small changes to the environmental shear lead to similar variability of the system response as changes to the initial $\theta^{\prime}$ of the thermal. Relative differences between POLL and PRIS in accumulated surface precipitation, $\mathrm{MF}_{\mathrm{c}}$, and the mean cold pool $\theta$, calculated following the approach in Table 2, vary from -4.7 to $-6.1 \%,-4.2$ to $-8.7 \%$, and 5.3 to $9.8 \%$, respectively, over the small range of shears tested. Variability of differences in other measures of convective intensity between POLL and PRIS (e.g., convective mass flux averaged only within convective cores) is substantially greater. Overall, these results highlight difficulty in quantifying and generalizing aerosol effects based on single realizations at a given aerosol loading.

The growth of perturbations in model fields occurs most rapidly at the scale of individual convective cells, i.e., a spatial scale of $O(1 \mathrm{~km})$ and temporal scale of $O(1 \mathrm{~h})$ (Zhang et al., 2007; Wang et al., 2012). This implies that the problem of separating robust aerosol effects from variability driven by small perturbations to model fields is exacerbated when analyzing the impact on individual deep convective clouds over short timescales (of order a few h). Given these characteristics of perturbation growth, it is expected that analyses encompassing larger domains that include a number of individual convective cells over their lifetime of growth and decay would allow for a more robust quantification and generalization of aerosol effects on deep convection. However, such analyses are then complicated by the interaction of convection with its larger-scale thermodynamic and dynamic environment, which may obscure the effects of aerosols on individual clouds (Grabowski 2006; Morrison and Grabowski, 

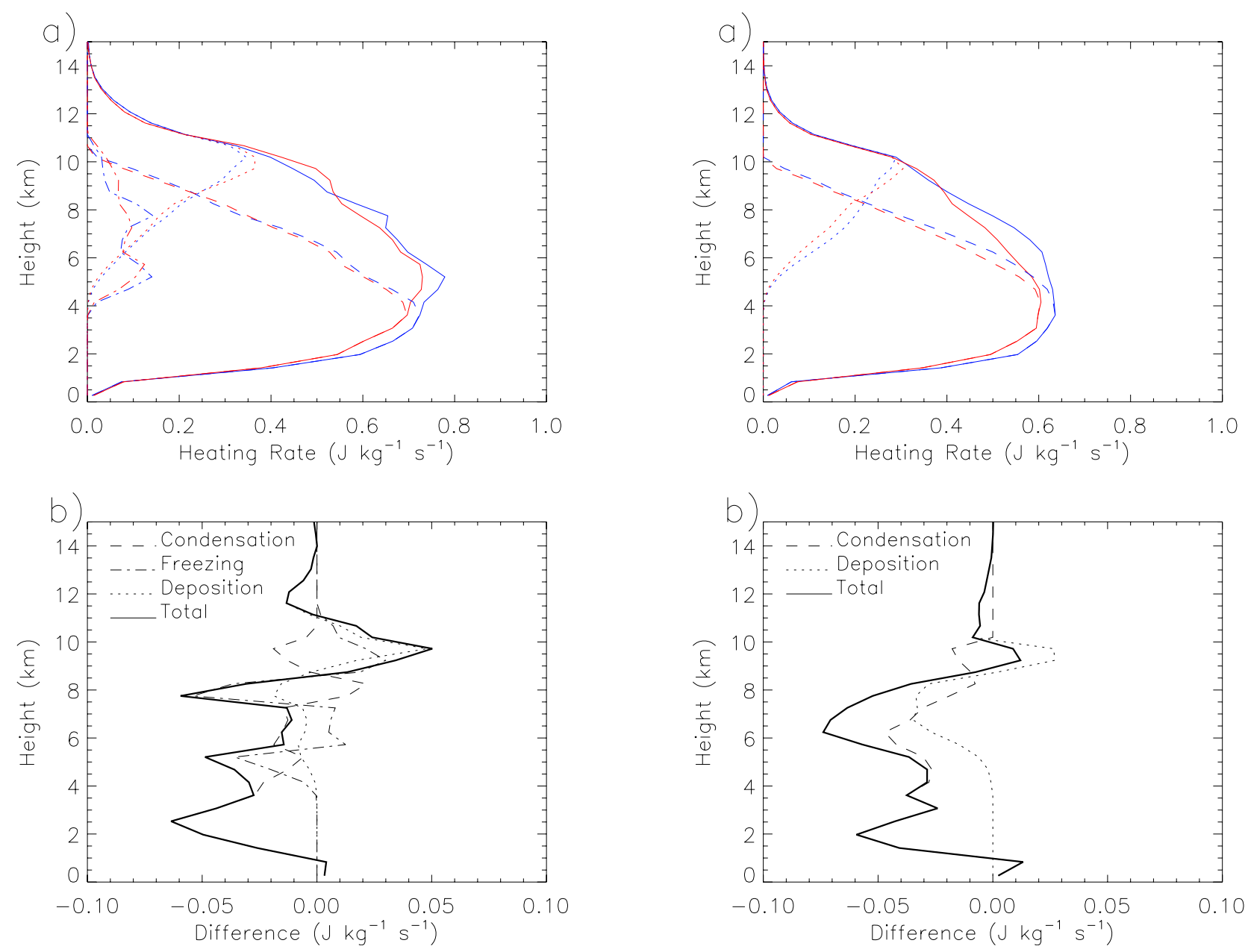

Fig. 11. (a) Vertical profiles of domain-mean latent heating contributions from cloud water condensation (dash), freezing of cloud liquid water and rain (dot-dash), vapor deposition onto ice (dotted), and the total latent heating (solid) for the BASE configuration at $t=120 \mathrm{~min}$. Results for pristine (PRIS) and polluted (POLL) conditions are indicated by blue and red lines, respectively. (b) Difference in the latent heating contributions (POLL minus PRIS).

2011; van den Heever et al., 2011; Seifert et al., 2012). Consistent with this picture, the modeling study of Seifert et al. (2012) found that while aerosols can have large instantaneous, local impacts on summertime precipitation over Germany, the net effect is very small when averaged over space and time. They concluded that studies of the impact of aerosols on single cases with small domains and/or short time periods can yield misleading results because important mesoscale feedbacks are not taken into account. The tests described herein suggest that generalizing aerosol effects from short case studies over small domains can also yield misleading results simply because of limits on the predictability of convective systems, especially for individual convective cells.

Fig. 12. As in Fig. 11, except for the configuration with latent heating due to freezing of cloud liquid water and rain turned off (NOFRZLLH).

\section{Discussion and conclusions}

In this study, the impact of polluted (POLL) versus pristine (PRIS) conditions on a supercell storm was simulated using WRF coupled with a bulk two-moment microphysics scheme (Morrison et al., 2009). The primary focus was on exploring robustness of simulated aerosol effects in the face of complex process interactions and feedbacks between the cloud microphysics and dynamics. Simulations were run using sixteen different model configurations with various microphysical and thermodynamic processes systematically modified or turned off. Robustness of the storm response to polluted conditions was also explored for each configuration by performing additional simulations with small perturbations to the initial conditions.

It is emphasized that the various model configurations were chosen to investigate the importance of various processes in driving the system response to polluted conditions in the face of system complexity, and not to quantify 

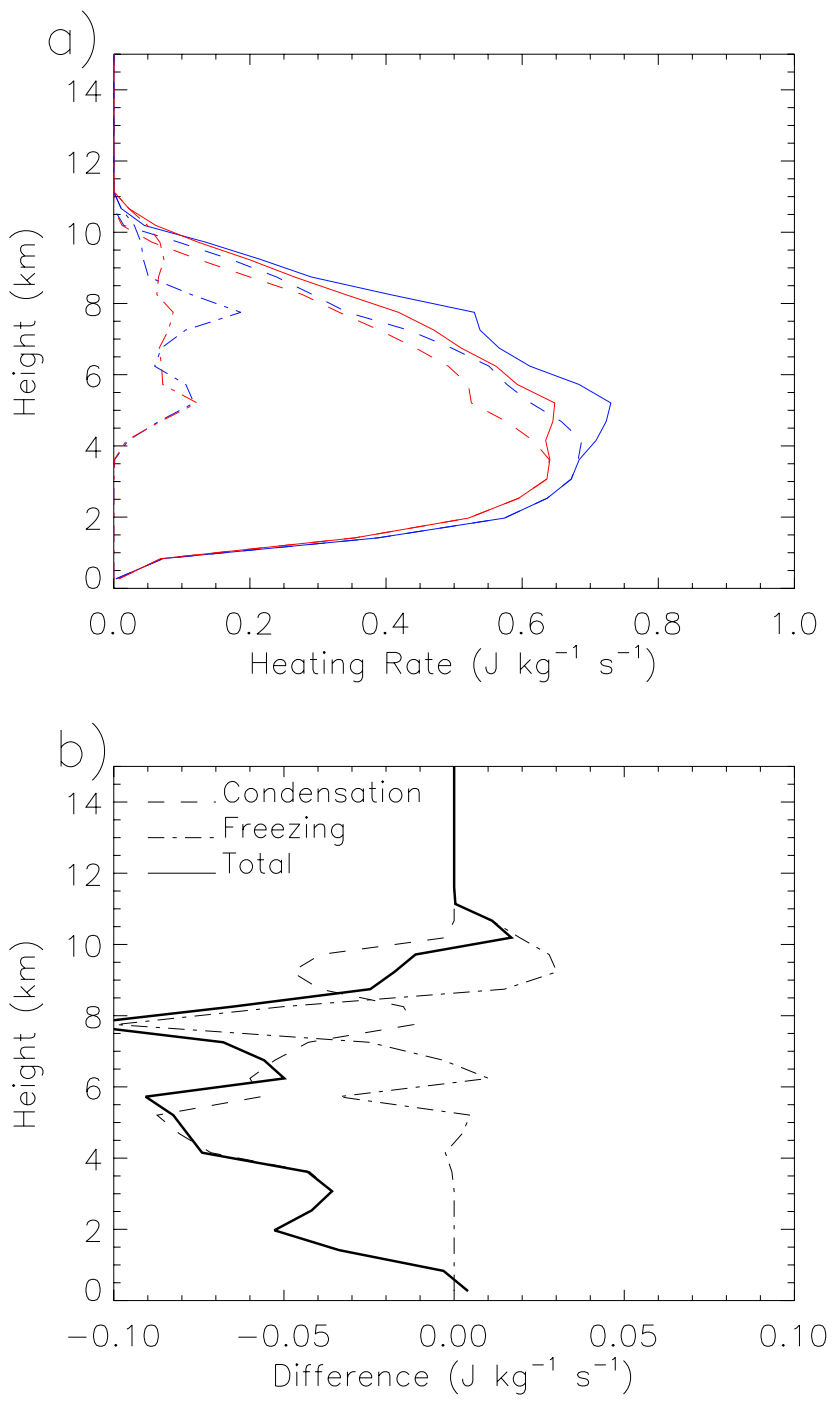

Fig. 13. As in Fig. 11, except for the configuration with latent heating due to vapor deposition onto ice turned off (NODEP_LH).

uncertainty associated with process parameterizations themselves. Estimating uncertainty associated with the representation of physical processes and parameters, within a reasonable range of realism, will require additional sensitivity testing and is beyond the scope of this paper. Therefore, the spread of results reported herein for the various sensitivity tests should not be interpreted as a quantitative estimate of model uncertainty in simulating aerosol effects on deep convection. Nonetheless, such uncertainty is important and should be a focus of future work.

Relative differences in domain-averaged convective mass flux, $\mathrm{MF}_{\mathrm{c}}$, and accumulated surface precipitation between PRIS and POLL were small (less than $15 \%$ ) for almost all of the model configurations that were tested. The baseline version of the microphysics scheme (BASE) produced a weakening of convection in polluted relative to pristine condi-

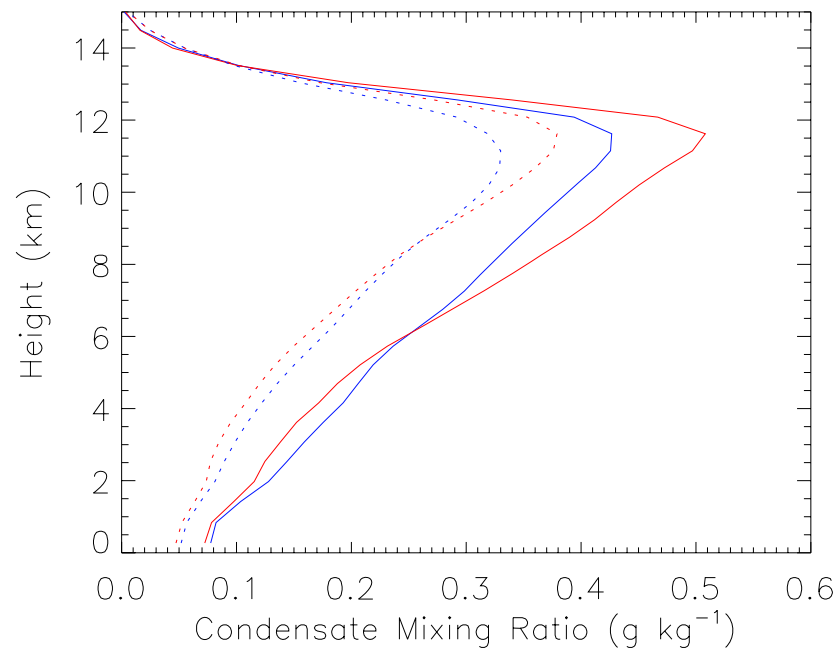

Fig. 14. (a) Vertical profiles of domain-mean total hydrometeor mixing ratios for the baseline configuration (BASE) at $t=90 \mathrm{~min}$ (dotted) and $t=120 \mathrm{~min}$ (solid). Pristine and polluted conditions are shown by blue and red lines, respectively.

tions, similar to previous studies using this scheme (Fan et al., 2012; LS11). Configurations that produced weaker cold pools in polluted conditions, including BASE, also tended to simulate decreases in $\mathrm{MF}_{\mathrm{c}}$ (at a height of $8.25 \mathrm{~km}$ ) and accumulated surface precipitation. Combined with an analysis of differences in dynamical and thermodynamic fields between PRIS and POLL, these results suggest the importance of interactions between microphysics, cold pools, and dynamics along outflow boundaries in explaining the system response. For configurations that produced smaller differences in cold pool strength, there was either an increase or decrease of $\mathrm{MF}_{\mathrm{c}}$ and surface precipitation. Turning off hail initiation, setting the hail fallspeed-size relation to that of snow, or turning off latent cooling from cloud water and rain evaporation each resulted in a change in the sign of the convective response relative to BASE, with invigoration instead of weakening in polluted conditions. These results highlight the importance of hail microphysics, whose parameterization is highly uncertain in both bin and bulk microphysics schemes. It is concluded that improvements in the representation of hail may be needed to reduce uncertainty in simulating aerosol indirect effects on deep convection, at least for supercell storms. Improved parameterization of hail will also require better observational datasets.

There is additional uncertainty in quantifying and generalizing aerosol effects on deep convection because of the rapid growth of small perturbations in model fields and hence limited predictability and divergence of solutions over time. This may be especially problematic if the overall magnitude of aerosol effects is small, as was the case here. Nonetheless, the findings reported herein were robust, in a qualitative sense, with small perturbations to the initial thermal used to generate convection. However, there were changes in the 
magnitude of differences in domain-mean surface precipitation and $\mathrm{MF}_{\mathrm{c}}$ for most configurations, and in some cases changes in the sign of these differences. Changes in the magnitude of these impacts were also evident for the baseline model configuration with small perturbations to the vertical shear of the environmental u-component wind. These changes were of similar magnitude to changes in aerosol effects on deep convective storms with altered microphysics process formulations reported in previous studies (Ekman et al., 2011; Xie and Liu, 2011). Thus, the rapid growth of small perturbations and limits on the predictability of convective systems can potentially obscure sensitivity of aerosol effects to different model configurations and parameterizations, especially for studies of individual storms.

Overall, it is concluded that reducing uncertainty in simulations of aerosol effects on deep convective storms will likely require ensemble methods in addition to continued improvement of model parameterizations. This has implications for computationally-intensive bin microphysics schemes, given the expense of performing ensemble simulations even with simple microphysics schemes. It remains unclear how many ensemble members might be needed for robust characterization of aerosol effects at different spatiotemporal scales and in different regimes; such an effort is beyond the scope of this paper but will be investigated in future work. Additional work will also focus on comparing aerosol effects on deep convection simulated using bulk and bin microphysics schemes in the context of the issues raised here, both in terms of model parameter uncertainty and fundamental predictability limits of convective systems. The goal is to identify specific reasons for large differences in simulations of aerosol effects in bulk and bin schemes reported in previous studies (Khain and Lynn, 2009; Li et al., 2009a; 2009b; LS11; Fan et al., 2012).

Acknowledgements. This work was partially supported by the NOAA grant NA08OAR4310543, U.S. DOE ARM DE-FG0208ER64574, and the NSF Science and Technology Center for Multiscale Modeling of Atmospheric Processes (CMMAP), managed by Colorado State University under cooperative agreement ATM-0425247. The author thanks W. Grabowski and Z. Lebo for discussion and comments on the manuscript.

National Center for Atmospheric Research is sponsored by the National Science Foundation.

Edited by: P. Spichtinger

\section{References}

Blyth, A. M. and Latham, J.: A climatological parameterization for cumulus clouds, J. Atmos. Sci., 48, 2367-2371, 1991.

Bryan, G. H., Wyngaard, J. C., and Fritsch, J. M.: Resolution requirements for the simulation of deep moist convection, Mon. Weather Rev., 131, 2394-2416, 2003.

Dawson, D. T. II, Xue, M., Milbrandt, J. A., and Yau, M. K.: Comparison of evaporation and cold pool development between single-moment and multi-moment bulk microhysics schemes in idealized simulations of tornadic thunderstorms, Mon. Weather Rev., 138, 1152-1171, 2010.

Ekman, A. M. L., Engstrom, A., and Soderberg, A.: Impact of twoway aerosol-cloud interaction and changes in aerosol size distribution on simulated aerosol-induced deep convective cloud sensitivity, J. Atmos. Sci., 68, 685-697, 2011.

Fan, J., Zhang, R., Li, G., and Tao, W.-K.: Effects of aerosols and relative humidity on cumulus clouds, J. Geophys. Res., 112, D14204, doi:10.1029/2006JD008136, 2007.

Fan, J., Yuan, T., Comstock, J. M., Ghan, S., Khain, A., Leung, L. R., Li, Z., Martins, V. J., and Ovchinnikov, M.: Dominant role by vertical wind shear in regulating aerosol effects on deep convective clouds, J. Geophys. Res., 114, D22206, doi:10.1029/2009JD012352, 2009.

Fan, J., Leung, L. R., Li, Z., Morrison, H., Qian, Y., Zhou, Y., and Chen, H.: Aerosol impacts on clouds and precipitation in southeast China - Results from bin and bulk microphysics for the 2008 AMF-China field campaign, J. Geophys. Res., 117, D00K36, doi:10.1029/2011JD016537, 2012.

Gilmore, M. S. and Wicker, L. J.: The influence of midtropospheric dryness on supercell morphology and evolution, Mon. Weather Rev., 126, 943-958, 1998.

Gilmore, M. S., Straka, J. M., and Rasmussen, E. N.: Precipitation uncertainty due to variations in precipitation particle parameters within a simple microphysics scheme, Mon. Weather Rev., 132, 2610-2627, 2004.

Grabowski, W. W.: Indirect impact of atmospheric aerosols in idealized simulations of convective-radiative equilibrium, J. Climate, 19, 4664-4682, 2006.

Hack, J. J. and Pedretti, J. A.: Assessment of solution uncertainties in single-column modeling frameworks, J. Climate, 13, 352-365, 2000.

James, R. P. and Markowski, P. M.: A numerical investigation of the effects of dry air aloft on deep convection, Mon. Weather Rev., 138, 140-161, 2010.

Khain, A. P.: Notes on state-of-the-art investigation of aerosol effects on precipitation: A critical review, Environ Res. Lett., 4, 015004, doi:10.1088/1748-9326/4/1/015004, 2009.

Khain, A. P. and Lynn, B.: Simulation of a supercell storm in clean and dirty atmosphere using weather research and forecast model with spectral bin microphysics, J. Geophys. Res., 114, D19209, doi:10.1029/2009JD011827, 2009.

Khain, A. P., Rosenfeld, D., and Pokrovsky, A.: Aerosol impact on the dynamics and microphysics of deep convective clouds, Q. J. Roy. Meteorol. Soc., 131, 2639-2663, 2005.

Khain, A. P., Leung, L. R., Lynn, B., and Ghan, S.: Effects of aerosols on the dynamics and microphysics of squall lines simulated by spectral bin and bulk parameterization schemes, J. Geophys. Res., 114, D22203, doi:10.1029/2009JD011902, 2009. 
Klemp, J. B.: Dynamics of tornadic thunderstorms, Ann. Rev. Fluid Mech., 19, 369-402, 1987.

Klemp, J. B. and Wilhemson, R. B.: Simulation of right- and leftmoving storms produced through storm splitting, J. Atmos. Sci., 35, 1097-1110, 1978.

Koren, I., Kaufman, Y. J., Rosenfeld, D., Remer, L. A., and Rudich, Y.: Aerosol invigoration and restructuring of Atlantic convective clouds, Geophys. Res. Lett., 32, L14828, doi:10.1029/2005GL0232187, 2005.

Lebo, Z. J. and Seinfeld, J. H.: Theoretical basis for convective invigoration due to increased aerosol concentration, Atmos. Chem. Phys., 11, 5407-5429, doi:10.5194/acp-11-5407-2011, 2011.

Lebo, Z. J., Morrison, H., and Seinfeld, J. H.: Are simulated aerosolinduced effects on deep convective clouds strongly dependent on saturation adjustment?, Atmos. Chem. Phys. Discuss., 12, 10059-10114, doi:10.5194/acpd-12-10059-2012, 2012.

Lee, S. S.: Dependence of aerosol-precipitation interactions on humidity in a multiple-cloud system, Atmos. Chem. Phys. Discuss., 10, 25287-25327, doi:10.5194/acpd-10-25287-2010, 2010.

Lee, S. S., Donner, L. J., Phillips, V. T. J., and Ming, Y.: Examination of aerosol effects on precipitation in deep convective clouds during the 1997 ARM summer experiment, Q. J. Roy. Meteorol. Soc., 134, 1201-1220, 2008.

Levin, Z. and Cotton, W. R.: Aerosol Pollution Impacts on Precipitation - A Scientific Review, Springer, The Netherlands, 2009.

Li, X., Tao, W.-K., Khain, A. P., Simpson, J., and Johnson, D. E.: Sensitivity of a cloud-resolving model to bulk and explicit bin microphysical schemes. Part 1: Validation with a PRE-STORM case, J. Atmos. Sci., 66, 3-21, 2009a.

Li, X., Tao, W.-K., Khain, A. P., Simpson, J., and Johnson, D. E.: Sensitivity of a cloud-resolving model to bulk and explicit bin microphysical schemes. Part 2: Cloud microphysics and dynamics interaction, J. Atmos. Sci., 66, 3-21, 2009b.

Lorenz, E.: The predictability of a flow which possesses many scales of motion, Tellus, 21, 289-307, 1969.

Lynn, B., Khain, A., Dudhia, J., Rosenfeld, D., Povrovsky, A., and Seifert, A.: Spectral (bin) microphysics coupled with a mesoscale model (MM5). Part I, Model description of first results, Mon. Weather Rev., 133, 44-58, 2005.

Milbrandt, J. A. and Yau, M. K.: A multimoment bulk microphysics parameterization. Part IV: Sensitivity experiments, J. Atmos. Sci., 63, 3137-3159, 2006.

Morrison, H. and Grabowski, W. W.: Cloud system-resolving model simulations of aerosol indirect effects on tropical deep convection and its thermodynamic environment, Atmos. Chem. Phys., 11, 10503-10523, doi:10.5194/acp-11-10503-2011, 2011.

Morrison, H. and Milbrandt, J. A.: Comparison of two-moment bulk microphysics schemes in idealized supercell thunderstorm simulations, Mon. Weather Rev., 139, 1103-1130, 2011.

Morrison, H., Thompson, G., and Tatarskii, V.: Impact of cloud microphysics on the development of trailing stratiform precipitation in a simulated squall line: Comparison of one- and two-moment schemes, Mon. Weather Rev., 137, 991-1007, 2009.

Noppel, H., Blahak, U., Seifert, A., and Beheng, K. D.: Simulations of a hailstorm and the impact of CCN using an advanced twomoment cloud microphysical scheme, Atmos. Res., 96, 286-301, 2010.

Phillips, V. T. J., Pokrovsky, A., and Khain, A.: The influence of time-dependent melting on the dynamics and precipitation pro- duction in maritime and continental storm clouds, J. Atmos. Sci., 64, 338-359, 2007.

Rosenfeld, D., Lohmann, U., Raga, G. B., O’Dowd, C. D., Kumala, M., Fuzzi, S., Reissell, A., and Andrae, M. O.: Flood or drought: How do aerosols affect precipitation?, Science, 321, 1309-1313, 2008.

Seifert, A. and Beheng, K. D.: A two-moment cloud microphysics parameterization for mixed-phase clouds. Part 2: Maritime vs. continental deep convective storms, Meteorol. Atmos. Phys., 92, 45-66, 2006.

Seifert, A., Köhler, C., and Beheng, K. D.: Aerosol-cloudprecipitation effects over Germany as simulated by a convectivescale numerical weather prediction model, Atmos. Chem. Phys. Discuss., 11, 20203-20243, doi:10.5194/acpd-11-20203-2011, 2011.

Skamarock, W. C., Klemp, J. B., Dudhia, J., Gill, D. O., Barker, D. M., Duda, M., Huang, X.-Y., Wang, W., and Powers, J. G.,: A description of the advanced research WRF version 3. NCAR Tech. Note TN-475+STR, 113 pp., 2008.

Slawinska, J., Grabowski, W. W., and Morrison, H.: Impact of atmospheric aerosols on precipitation from deep organized convection: A prescribed-flow modeling study using double-moment bulk microphysics, Q. J. Roy. Meteorol. Soc., 135, 1906-1913, 2009.

Storer, R. L., van den Heever, S. C., and Stephens, G.: Modeling aerosol impacts on convective storms in different environments, J. Atmos. Sci., 67, 3904-3915, 2010.

Stevens, B. and Feingold, G.: Untangling aerosol effects on clouds and precipitation in a buffered system, Nature, 461, 607-613, 2009.

Tan, Z.-M., Zhang, F., Rotunno, R., and Snyder, C.: Mesoscale predictability of moist baroclinic waves: Experiments with parameterized convection, J. Atmos. Sci., 61, 1794-1804, 2004.

Tao, W.-K., Li, X., Khain, A., Matsui, T., Lang, S., Simpson, J.: Role of atmospheric aerosol concentration on deep convective precipitation: Cloud-resolving model simulations, J. Geophys. Res., 112, D24S18, doi:10.1029/2007JD008728, 2007.

Tao, W.-K., Chen, J.-P., Li, Z., Wang, C., and Zhang, C.: Impact of aerosols on convective clouds and precipitation, Rev. Geophys., 50, RG2001, 2011RG000369, 1-62, 2012.

Teller, A. and Levin, Z.: The effects of aerosols on precipitation and dimensions of subtropical clouds; a sensitivity study using a numerical cloud model, Atmos. Chem. Phys. Discuss., 5, 72117245, doi:10.5194/acpd-5-7211-2005, 2005.

van den Heever, S. C. and Cotton, W. R.: The impact of hail size on simulated supercell storms, J. Atmos. Sci., 61, 1596-1609, 2004. van den Heever, S. C., Carrio, G. G., Cotton, W. R., DeMott, P. J., and Prenni, A. J.: Impacts of nucleating aerosol on Florida storms. Part I: Mesoscale simulations, J. Atmos. Sci., 63, 17521775, 2006.

van den Heever, S. C., and Cotton, W. R.: Urban aerosol impacts on downwind convective storms, J. Appl. Met. Clim., 46, 828-850, 2007.

Wang, C.: A modeling study of the response of tropical deep convection to the increase of cloud condensation nuclei concentration: 1. Dynamics and microphysics, J. Geophys. Res., 110, D21211, doi:10.1029/2004JD005720, 2005.

Wang, H., Auligne, T., and Morrison, H.: The impact of microphysics scheme complexity on the propagation of initial 
perturbations, Mon. Wea. Rev., 140, 2287-2296, 2012.

Weisman, M. L. and Klemp, J. B.: The dependence of numerically simulated convective storms on wind shear and buoyancy, Mon. Weather Rev., 110, 504-520, 1982.

Weisman, M. L. and Klemp, J. B.: The structure and classification of numerically simulated convective storms in directionally varying wind shears, Mon. Weather Rev., 112, 2479-2498, 1984.

Weisman, M. L. and Rotunno, R.: "A theory for strong long-lived squall lines" revisited, J. Atmos. Sci., 61, 361-382, 2004.
Xie, X. and Liu, X: Effects of spectral dispersion on clouds and precipitation in mesoscale convective systems, J. Geophys. Res., 116, D06202, doi:10.1029/2010JD014598, 2011.

Zhang, F., Snyder, C., Rotunno, R.: Effects of moist convection on mesoscale predictability, J. Atmos. Sci., 60, 1173-1185, 2003.

Zhang, F., Bei, N., Rotunno, R., Snyder, C., and Epifanio, C. C.: Mesoscale predictability of moist baroclinic waves: Convectionpermitting experiments and multistage error growth dynamics, J. Atmos. Sci., 64, 3579-3594, 2007. 